\title{
Cartilage Repair Surgery: Outcome Evaluation by Using Noninvasive Cartilage Biomarkers Based on Quantitative MRI Techniques?
}

\author{
Pia M. Jungmann, ${ }^{1}$ Thomas Baum, ${ }^{1}$ Jan S. Bauer, ${ }^{2}$ Dimitrios C. Karampinos, ${ }^{1}$ \\ Benjamin Erdle, ${ }^{3}$ Thomas M. Link, ${ }^{4}$ Xiaojuan Li, ${ }^{4}$ Siegfried Trattnig, ${ }^{5}$ Ernst J. Rummeny, \\ Klaus Woertler, ${ }^{1}$ and Goetz H. Welsch ${ }^{5,6}$ \\ ${ }^{1}$ Department of Radiology, Klinikum Rechts der Isar, Technische Universitaet Muenchen, Ismaninger Strasse 22, \\ 81675 Munich, Germany \\ ${ }^{2}$ Department of Neuroradiology, Klinikum Rechts der Isar, Technische Universitaet Muenchen, Ismaninger Strasse 22, \\ 81675 Munich, Germany \\ ${ }^{3}$ Department of Orthopaedic and Trauma Surgery, University Medical Center, Albert-Ludwigs Universitaet Freiburg, \\ Hugstetter Strasse 55, 79106 Freiburg, Germany \\ ${ }^{4}$ Musculoskeletal and Quantitative Imaging Research Group, Department of Radiology and Biomedical Imaging, \\ University of California San Francisco, 185 Berry Street, Suite 350, San Francisco, CA 94107, USA \\ ${ }^{5}$ MR Center, Department of Radiology, Medical University of Vienna, Lazarettgasse 14, 1090 Vienna, Austria \\ ${ }^{6}$ Department of Trauma Surgery, Friedrich-Alexander-Universitaet Erlangen-Nuernberg, Krankenhausstrasse 12, \\ 91054 Erlangen, Germany \\ Correspondence should be addressed to Pia M. Jungmann; pia.jungmann@tum.de
}

Received 24 January 2014; Accepted 25 March 2014; Published 4 May 2014

Academic Editor: Hagen Schmal

Copyright (c) 2014 Pia M. Jungmann et al. This is an open access article distributed under the Creative Commons Attribution License, which permits unrestricted use, distribution, and reproduction in any medium, provided the original work is properly cited.

Background. New quantitative magnetic resonance imaging (MRI) techniques are increasingly applied as outcome measures after cartilage repair. Objective. To review the current literature on the use of quantitative MRI biomarkers for evaluation of cartilage repair at the knee and ankle. Methods. Using PubMed literature research, studies on biochemical, quantitative MR imaging of cartilage repair were identified and reviewed. Results. Quantitative MR biomarkers detect early degeneration of articular cartilage, mainly represented by an increasing water content, collagen disruption, and proteoglycan loss. Recently, feasibility of biochemical MR imaging of cartilage repair tissue and surrounding cartilage was demonstrated. Ultrastructural properties of the tissue after different repair procedures resulted in differences in imaging characteristics. T2 mapping, T1rho mapping, delayed gadoliniumenhanced MRI of cartilage (dGEMRIC), and diffusion weighted imaging (DWI) are applicable on most clinical $1.5 \mathrm{~T}$ and $3 \mathrm{~T}$ MR scanners. Currently, a standard of reference is difficult to define and knowledge is limited concerning correlation of clinical and MR findings. The lack of histological correlations complicates the identification of the exact tissue composition. Conclusions. A multimodal approach combining several quantitative MRI techniques in addition to morphological and clinical evaluation might be promising. Further investigations are required to demonstrate the potential for outcome evaluation after cartilage repair.

\section{Introduction}

Quantitative magnetic resonance imaging (MRI) techniques are frequently applied as noninvasive biomarkers for detection of early articular cartilage degeneration before morphological cartilage loss occurs [1-5]. Hyaline cartilage consists of chondrocytes to about $1 \%$; the extracellular matrix is composed of collagen (15-20\%), mainly collagen type II, proteoglycan (PG; 3-10\%), consisting of protein and glycosaminoglycan (GAG) side chains, and water (about 80\%) $[6,7]$. The combination of all components provides important viscoelastic properties, which are critical for a proper 
cartilage function [7, 8]. Early cartilage degeneration is characterized by collagen disruption and GAG loss, resulting in an increasing bulk water content and mobility $[6,9]$.

Correlations of quantitative MR biomarkers with histological and biochemical properties of cartilage were previously described $[10,11]$. Whereas T2 relaxation time measurements are mainly sensitive to collagen disruption and water content [12-18], other techniques exist that are sensitive to GAG concentrations. GAG is largely responsible for the negative fixed-charge density of articular cartilage. Delayed gadolinium-enhanced MRI of cartilage (dGEMRIC) [19-21] and ${ }^{23} \mathrm{Na}$ MRI (sodium MRI) [22, 23] reflect this fixed-charge density and consecutively indirectly measure GAG concentrations [24]. GAG chemical exchange saturation transfer (gagCEST) measures GAG concentrations by using the GAG molecules as endogenous contrast agents [25-28]. T1rho relaxation time measurements can investigate the slowmotion interactions between the macromolecule protons and bulk water protons and therefore indirectly measure GAG concentrations $[29,30]$. Although T2 and T1rho preferentially correlate with different cartilage parameters, high correlations were found between these two parameters [31]. Further techniques are diffusion weighted imaging (DWI) [32] and diffusion tensor imaging (DTI) [33], which are sensitive to water mobility. Additional techniques have been described to correlate with cartilage degeneration. A zonal organization of normal articular cartilage is known, which may be detected by quantitative imaging techniques in laminar analyses [34, 35].

If cartilage defects have occurred, focal defects may be treated by different surgical cartilage repair techniques, including microfracture (Mfx), osteochondral autograft transplantations (OAT), and autologous chondrocyte implantation (ACI) or matrix associated ACI (MACI), respectively [36-39]. These techniques are known to result in different histological types of cartilage repair tissue [40-43]. Prediction of long-term outcome is essential for the individual patient as well as for individual therapy optimization. Therefore, this is a field of research with a strong translational interest by surgeons, radiologists, physicists, and experimental researchers. Besides clinical evaluation, magnetic resonance imaging (MRI) represents one of the most important diagnostic tools for postoperative followup. Morphological outcome evaluation may include scores such as the MOCART $[44,45]$ or the Henderson score [46-48]. Quantitative MR imaging may provide additional important information on subtle tissue changes that are morphologically not detectable. The intention of quantitative imaging is to assess cartilage repair tissue noninvasively and to provide highly sensitive outcome measurements without the need of an arthroscopy or even biopsy. It may potentially be used to predict and monitor cartilage repair maturation and outcome [14].

The present work specifically reviews the current literature on the use of quantitative MRI biomarkers for evaluation of cartilage repair that are applicable at clinical $1.5 \mathrm{~T}$ and $3 \mathrm{~T}$ MR scanners.

\section{Materials and Methods}

2.1. Identification of Literature. An electronic search in PubMed (http://www.ncbi.nlm.nih.gov/pubmed) was performed to identify relevant studies on biochemical MR imaging of cartilage repair for this review. Specific PubMed searches including the entry terms "cartilage repair imaging" (835 results) and "cartilage repair MRI" (729 results) as well as the specific terms "cartilage repair T2" (104 results), "cartilage repair T1rho" (11 results), "cartilage repair dGEMRIC" (27 results), "cartilage repair diffusion" (70 results), "cartilage repair DWI" (5 results), and "cartilage repair DTI” (1 result) were screened for relevant studies. Additional searches were performed for the the entry terms "microfracture imaging" (126 results), "microfracturing imaging" (13 results), "cartilage transplantation imaging" (733 results), "chondrocyte transplantation imaging" (291 results), "OATS imaging” (36 results), and "osteochondral transplantation imaging" (274 results) to exclude that relevant studies for each cartilage repair technique were missed by the main entry terms. Further searches were performed using the term "MRI" instead of "imaging"; it did not result in additional relevant references. Reference lists of previous important studies and reviews were screened [2-6, 14, 15, 26, 36, 37, 39, 46, 49-71]. Subsequently, additional searches with the same entry terms were performed in the databases "EMBASE" and "Cochrane Library." However, these did not result in further, relevant results. Only studies in humans were included. References included the time span up to December, 2013, without starting date.

\section{Results}

3.1. Techniques. The quantitative $\mathrm{MR}$ imaging techniques $\mathrm{T} 2$ and T2* mapping, T1rho mapping, dGEMRIC, and diffusion imaging may be performed on most clinical $1.5 \mathrm{~T}$ or $3 \mathrm{~T}$ MRI scanners using product or research pulse sequences and standard hardware; most of the techniques are also possible at $7 \mathrm{~T}$ [72]. Sodium MRI can especially benefit from higher SNRs and gagCEST can especially benefit from higher spatial resolution when performed at $7 \mathrm{~T}[28,51]$. Sodium MRI requires special hardware and gagCEST has been only recently applied in cartilage, making these two techniques not broadly available for clinical use.

It is not entirely clear whether prolonged unloading during an MR examination influences quantitative values $[73,74]$. Mamisch et al. stated that the difference in T2 values between the beginning and the end of the MR examination was more pronounced in cartilage repair tissue than in normal cartilage [75]. Therefore, standardization of the time of unloading is recommended when performing quantitative MR imaging.

3.1.1. T2 and T2* Relaxation Time Measurements. Currently T2 relaxation time measurements are the most investigated noninvasive MRI biomarkers for evaluation of articular cartilage and cartilage repair tissue. Higher and more heterogeneous $\mathrm{T} 2$ values are thought to characterize collagen deterioration and increasing water contents $[14,76]$. 
T2 measurements do not require contrast agent injections.

Different pulse sequences can be used for T2 mapping including spin echo (SE), multislice multiecho (MSME) SE, fast spin echo (FSE), and T2-prepared 3D spoiled gradient recalled (SPGR) sequences $[49,77]$. Welsch et al. described T2 DESS sequences that provide the possibility to combine morphological and biochemical MRI in one fast $3 \mathrm{D}$ sequence [66]. T2 values still vary significantly between different acquisition methods and MR scanners $[49,66]$. Further, magic angle effects may cause a prolongation of $\mathrm{T} 2$ at $55^{\circ}$ through the anisotropy of collagen with respect to the main magnetic field [78]. SE or MSME sequences are most frequently used for T2 mapping. Long echo trains of SEs are acquired, while the numbers and values of echo times (TE) vary $[6,79]$. In the osteoarthritis initiative (OAI), a MSME SE sequence with seven echoes (echo times of 10, 20, 30, 40, 50, 60, and $70 \mathrm{~ms}$ ) is used [80]. A MSME experiment, excluding the first echo from the later fitting process, improves the T2 quantification, since this eliminates the effects from stimulated echo signal $[16,49]$.

In the following postprocessing procedure, the measured signal intensity at each echo time (TE) is fitted to a monoexponential decay function and measured pixel by pixel to calculate T2 values [6] $\left(S\left(\mathrm{TE}_{t}\right)=S_{0} \times \exp \left(-\mathrm{TE}_{t} / \mathrm{T} 2\right) ; S\right.$ is signal intensity; $S_{0}$ is equivalent to $S$ at TE $=0$ ). Weighted or nonweighted linear least squares or nonlinear least squares fitting methods are used [13]. Noise correction is recommended due to low signal-to-noise ratio (SNR) in the images acquired at the long TEs [13]. T2 relaxation time maps are generated from the calculated T2 values to perform further analysis.

The deep and calcified zones of articular cartilage are composed of dense collagen fibrils contributing to short T2 relaxation times. That is why standard (MSME) T2 mapping techniques may have limitations [81, 82]. In these deep cartilage areas, UTE T2* mapping may be more sensitive for tissue changes with T2 relaxation times of less than $10 \mathrm{~ms}$ [83]. T2* has shorter imaging times and the possibility of $3 \mathrm{D}$ acquisition and thereby providing greater spatial resolution [83]. In contrast to $\mathrm{T} 2$ mapping, $\mathrm{T} 2{ }^{*}$ mapping uses a gradient echo (GE) pulse sequence and includes both $\mathrm{T} 2$ relaxation and coherent dephasing effects. $\mathrm{T} 2{ }^{*}$ and $\mathrm{T} 2$ values are related by the equation $1 / \mathrm{T} 2^{*}=1 / \mathrm{T} 2+\gamma \Delta B_{0}(\gamma$ is gyromagnetic ratio of the observed nucleus; $\Delta B_{0}$ is magnetic field inhomogeneity). It is assumed that $\Delta B_{0}$ is only influenced by local magnetic susceptibility fields present at the cartilage-bone interface or within the cartilage microstructure. Despite not reflecting the exactly same ultrastructural components, T2 and $\mathrm{T}^{*}$ have been described to correlate with each other [49, 72, 83, 84]. However, the correlation coefficient was relatively low, especially for the deep cartilage layer.

3.1.2. T1rho Relaxation Time Measurements. The time constant T1rho describes the spin-lattice relaxation time in the rotating frame by application of spin-lock (SL) techniques [7, 85-88]. T1rho values have been shown to increase with GAG (PG) content loss of the extracellular matrix of hyaline cartilage, with increases in bulk water and with cartilage softening, while being less dependent on collagen disruption
[31, 85, 89-94]. T1rho relaxation time measurements do not require contrast agent injections.

Current T1rho quantification techniques use SE, FSE $[89,90]$ spiral imaging [31], echo planar imaging [95], or 3D GE sequences $[93,96]$. The data can be acquired with $2 \mathrm{D}$ or $3 \mathrm{D}$ acquisitions. 3D techniques provide thinner slices and may be preferred due to the nonslice-selective nature of the SL pulse. In these techniques spins are tilted to the transversal plane by a $90^{\circ}$ pulse and then locked in that plane by an SL pulse. The responsible long, continuous SL radiofrequency power pulse along B1 exceeds small local molecular magnetic fields. Therefore, no T2 or T1 relaxation but longitudinal T1rho relaxation along B1 takes place [7]. For readout purposes, another $-90^{\circ}$ pulse is applied that flips this spin-locked magnetization back to the $z$-axis. In the following series, different SL pulse durations (time of spin lock, TSL) are applied. Finally, T1rho may be determined by fitting the data to the T1rho decay curve, which is governed by an exponential equation (S(TSL) $\propto \exp (-\mathrm{TSL} / \mathrm{T} 1 \mathrm{rho}))$. Due to SAR limitations, usually a SL frequency $\leq 500 \mathrm{~Hz}$ is used. The TSLs applied for cartilage are between 0 and $80 \mathrm{~ms}$. Noise correction is recommended due to low signal-to-noise ratio (SNR) in the images acquired at the long TSLs.

3.1.3. Delayed Gadolinium-Enhanced MRI of Cartilage (dGEMRIC). dGEMRIC is another quantitative cartilage MR imaging technique that correlates with the PG content of articular cartilage [2, 19, 97-101]. In comparison to T1rho, dGEMRIC is able to provide a direct measure of the GAG content. However, it requires the application of a negatively charged intravenous contrast agent, gadolinium diethylenetriamine pentaacetate anion (Gd-DTPA), that enhances T1 relaxation times [11, 19, 62, 98, 102-104]. The negatively charged Gd-DTPA molecule penetrates cartilage in an inverse relationship to the concentration of negatively charged GAG side chains of PG [24]. A depletion of GAG content in degenerated cartilage results in an accumulation of the paramagnetic gadolinium ions, following the principle of electroneutrality. This consequently accelerates T1 relaxation [105]. There are several different sequences for dGEMRIC available, depending on the MR scanner [72, 73, 106111]. Data can be acquired using $2 \mathrm{D}$ or $3 \mathrm{D}$ techniques [102, 108, 112-114].

Usually, a double dose $(0.2 \mathrm{mmol} / \mathrm{kg})$ Gd-DTPA is applied [99]. About 45-120 minutes after contrast administration, postcontrast MRI is performed, although reaching maximum and equilibrium concentration may take longer $[99,115-117]$. Additionally, an exercise period is required after contrast agent application, which influences the distribution of the contrast agent [118]. Usually, T1 relaxation time measurements precontrast (T1) and postcontrast application (T1$\mathrm{Gd}$ ) are used to determine the contrast agent concentration in cartilage $[19,105]$. The delta relaxation rate is defined by 1/T1 - 1/T1-Gd [119]. The relaxation index (relative delta) is defined by the delta relaxation rate of repair tissue divided by the delta relaxation rate of normal hyaline cartilage [119]. While differences of native T1 dGEMRIC values (T1) in normal hyaline cartilage can be neglected, it remains a matter of current investigations whether determination of native 
T1 dGEMRIC values in precontrast MRIs is necessary for evaluation of cartilage repair tissue [110, 119-123]. Precontrast dGEMRIC values of repair tissue were increased in MACI repair tissue compared to normal cartilage at all time points after surgery [119]. Watanabe et al. correlated dGEMRIC after ACI with biopsies [119]. A significant correlation of relative delta relaxation rates with relative GAG concentration, but not with relative $\mathrm{T} 1$ relaxation times before (T1) or after contrast application (T1-Gd), was observed [119]. Other authors found high correlations and similar results for T1Gd and delta relaxation rates after MACI and osteochondral transplantation, respectively $[110,124-126]$. To date, most studies acquired pre- and postcontrast images and additionally reported delta values [110].

3.1.4. Diffusion Weighted Imaging (DWI) and Diffusion Tensor Imaging (DTI). Diffusion weighted imaging (DWI) can probe water mobility in articular cartilage [2, 32, 127, 128]. Water molecules diffuse in the space surrounding the extracellular matrix of the cartilage. In cartilage with an intact collagen network, water mobility is restricted. The increased mobility of water in a deteriorated extracellular matrix, representing early cartilage degeneration, can be assessed by DWI [129]. Therefore, by measuring the molecular movements of water within the cartilage tissue, DWI techniques can probe tissue microstructure changes. Using this technique, two equal paired magnetic field gradient pulses are applied with a time delay [39]. The two gradient pulses either have opposed polarity or have the same polarity with an interposed $180^{\circ}$ radiofrequency pulse [39]. The paired gradient pulses, usually referred to as the diffusion gradients, cause dephasing of the protons that diffuse (move) during a given time delay. The acquired MR signal is related to the diffusion coefficient of the proton (Stejskal-Tanner equation) [39]. Stationary water protons lead to a high signal, moving protons within the time delay lead to a signal decrease. This experiment is repeated with varying diffusion gradient strength. For each acquisition, the overall diffusion weighting of the image is determined by a so-called $b$-factor [130]. In the following, an apparent diffusion coefficient (ADC) map is calculated from the images with different $b$-factors on a pixel-by-pixel basis [127] using the equation $S(b) \propto \exp \left(-b^{*} \mathrm{ADC}\right)$. ADC values were found to be elevated in degenerated cartilage $[32,131,132]$. Single-shot echo planar imaging- (EPI-) based diffusion sequences are the current gold standard of DWI but suffer from susceptibility artifacts and limitations in contrast. Alternatively, diffusion imaging can be performed using steady-state free precession sequences (SSFP), which provide diffusion weighting at relatively short echo times [133]. For articular cartilage, a three-dimensional steady-state diffusion technique, called PSIF, has been used (reversed FISP (fast imaging by steady-state precession)) [131, 132].

A variant of DWI is diffusion tensor imaging (DTI), which enables the measurement of diffusion anisotropy. In this technique, diffusion gradients are applied in at least six orientations and the data is fitted to a diffusion tensor model. Based on the determined diffusion tensor, the localized orientation of preferential diffusion and the localized diffusion anisotropy can be determined [33, 127, 130, 134].
DTI correlated with the orientation of collagen fibrils, with collagen disruption and cartilage degeneration $[33,135,136]$. However, because cartilage is characterized by a relatively low diffusion anisotropy, a reliable determination of its anisotropy requires a high SNR on the acquired diffusion data $[2,127,137$, $138]$.

3.1.5. Segmentation of Cartilage after Cartilage Repair Procedures. Segmentation is required to obtain quantitative values for each cartilage region of interest (ROI) from the acquired images. Most of the segmentation is so far done either manually or semiautomatically. For MR imaging at the knee, sagittal or coronal planes are obtained. Kurkijarvi et al. used both planes and found slight differences between the quantitative values [125]. Segmentation may either be performed directly on the quantitative source images or on SPGR or DESS images with higher spatial resolution, which can be superimposed in the following. For cartilage repair analyses, most studies segmented the cartilage repair area, plus morphologically normal appearing cartilage of the same compartment or other compartments. Analyses were performed by either correlating absolute values from the repair tissue or by using an index, utilizing the ratio of repair tissue over normal cartilage $[139,140]$.

Normal hyaline cartilage has a zonal stratification, which can be detected using maps of quantitative MRI biomarkers combined with laminar or zonal analyses [34, 35, 141-145]. Based on the known anatomical ultrastructure, cartilage may be divided into three or four zones. Few studies performed laminar analysis by dividing the entire cartilage in three layers [74]. However, spatial resolution is limited in the quantitative sequences. Therefore, most studies analyzed a superficial and a deep layer [140], reflecting the hyaline cartilage ultrastructure and thus showing, for example, a significant increase of $\mathrm{T} 2$ relaxation times from the deep to the superficial cartilage layer [144, 145].

\subsection{Findings for Quantitative Imaging of Cartilage Repair.} Different cartilage repair techniques are known to result in repair tissues with different histological compositions that vary during maturation [14]. Hyaline-like cartilage with a normal amount of PG was described to have a better clinical outcome and less therapy failure than fibrous cartilage [146]. After Mfx, tissue has been mostly reported as fibrous cartilage [40, 41]. After MACI, tissue has been characterized as hyaline-like [42]. Osteochondral transplants consist of about $80 \%$ of hyaline cartilage and of about $20 \%$ of fibrous cartilage [43, 147-149]. Further, Mfx repair tissue was described to consist disorganized cartilage and a reduced PG content, while MACI repair had a normal zonal collagen organization [150-153]. Results from quantitative imaging also suggest a difference in composition and structure between the repair tissues after various repair techniques [39].

3.2.1. Cartilage Repair Findings for T2 Relaxation Time Measurements. T2 relaxation time measurements seem to be promising for determining different structural tissue characteristics and to monitor the maturation process $[14,50$, $69,132,140,154]$. It was demonstrated that fibrous cartilage 

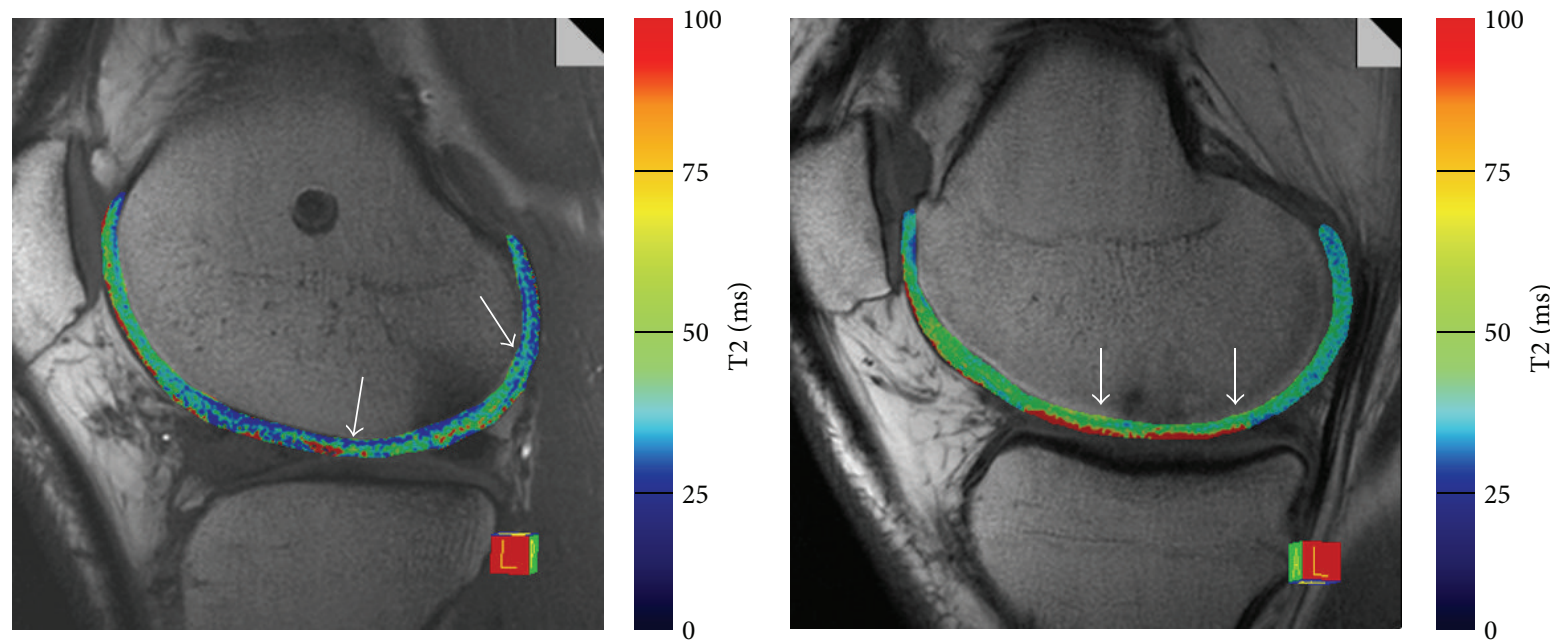

FIGURE 1: Left figure: T2-MACI. Quantitative T2 mapping of a 39-year-old male patient 24 months after MACI of the lateral femoral condyle (marked by arrows). The cartilage repair tissue showed a comparable ultrastructure compared to the surrounding native cartilage. Right figure: T2-MFX. Quantitative T2 map of a 31-year-old male patient 6 months after microfracture therapy of the medial femoral condyle (marked by arrows). The cartilage repair tissue showed still clearly increased T2 values. T2 maps were reconstructed using a multiecho spin echo (SE) acquisition, with a TR of $1200 \mathrm{~ms}$ and 6 TEs of 13.8, 27.6, 41.4, 55.2, 69, and $82 \mathrm{~ms}$. The field of view was $160 \times 160 \mathrm{~mm}$, the pixel matrix was $384 \times 384$, and the voxel size was $0.4 \times 0.4 \times 3.0 \mathrm{~mm}$. The bandwidth was $228 \mathrm{~Hz} /$ pixel, with 12 slices; total acquisition time was 4:09 minutes.

repair tissue showed lower T2 relaxation times than normal hyaline cartilage [39]. Correspondingly, lower T2 values were observed for repair tissue after Mfx as compared to MACI repair tissue, while no differences in Lysholm or MOCART scores were detected (Figure 1) [132, 144, 155]. T2 values differed between MACI at different knee compartments, for different MACI scaffolds and different Mfx techniques [156158]. One additional realization of biochemical MR imaging may be an "unloading" approach, acquiring one T2 map directly at the beginning and another T2 map at the end of the MR protocol [74, 75, 159].

Holtzman et al. reported that 3 to 6 months and 1 year after OAT T2 values showed no significant difference between repair cartilage and normal cartilage [139]. Salzmann et al. found that $\mathrm{T} 2$ values were higher in repair tissue after OAT as compared to normal cartilage and as compared to MACI repair tissue 3.5 years after surgery [160]. Krusche-Mandl et al. also found a significant difference of $\mathrm{T} 2$ values between repair cartilage after OAT and normal cartilage 8 years after surgery [26].

Maturation processes were also described for Mfx. Oneto et al. found initially elevated T2 values for Mfx repair tissue, which approached values of normal cartilage after two years in case of graft integrity and lower T2 values for therapy failure [161]. Theologis et al. observed that at 3 to 6 months after surgery Mfx repair tissue had significantly higher Tlrho and T2 values relative to normal cartilage [140]. At 1 year, T2 values of repair tissue decreased to values comparable to normal cartilage (T1rho remained significantly different). In two different studies, about 2.3 and 2.7 years after surgery, Welsch et al. detected reduced T2 in cartilage repair areas after Mfx, whereas, after MACI, T2 was similar to normal cartilage $[132,144]$. The laminar analysis showed the existence of a zonal stratification at 3-6 months after Mfx, which was lost after 12 months (but persisted for T1rho) [140]. Most studies however reported that normal zonal variation was lacking after Mfx [39, 83, 142, 144, 162].

Tissue maturation processes can also be depicted after ACI [39]. Kurkijarvi et al. showed that T2 values for ACI repair tissue were higher and more heterogeneous than $\mathrm{T} 2$ of normal control cartilage about one year after surgery with a lack of zonal organization [125]. T2 relaxation times were higher for repair tissue than for normal cartilage 3-13 months after ACI, but no significant difference was detected at later time points in several studies (after 19-42, 12-59, and 20 months) $[144,145,162,163]$. However, T2 of MACI repair tissue generally decreased during longer postoperative intervals $[144,162,164]$. According to Salzmann et al., repair tissue had significantly lower T2 values than normal cartilage about 3.5 years after MACI [160]. Zonal differences between the cartilage layers have been reported previously $[39,62$, $144,165]$. However, these zonal differences seem to vary during the maturation process after ACI. After one year, no zonal stratification was detected [125]. At later time points during the second year after MACI T2 zonal organization approached that of control cartilage and persisted during longer followups, as opposed to no zonal variation after Mfx [141, 144, 145, 162, 163]. Overall, these findings for T2 relaxation time measurements of cartilage repair tissue may correspond to the described histological differences of the tissue and indicate a maturation of both layers with a decrease in water content and an increase of collagen content and orientation [132].

Studies reported that $\mathrm{T}^{*}$ mapping may provide additional information on cartilage repair tissue (Figure 2) [39]. Stelzeneder et al. reported that at 1-year followup after arthroscopic autologous collagen-induced chondrogenesis (ACIC) $\mathrm{T}^{*}$ was not significantly different between repair 


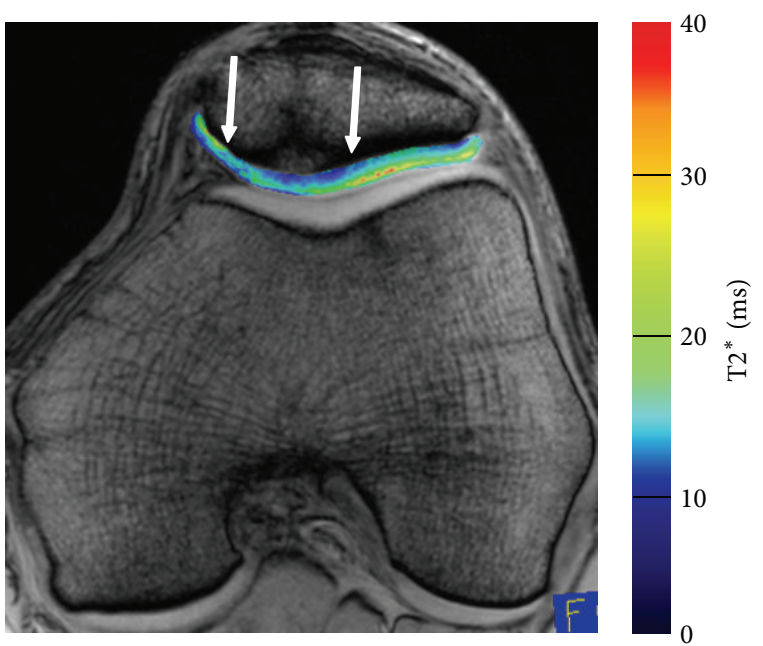

FIgURE 2: T2* -MFX. Quantitative T2* imaging of a 42 -year-old male patient 24 months after microfracture therapy of the patella cartilage (marked by arrows). The cartilage repair tissue showed reduced $\mathrm{T}^{*}$ values $(\mathrm{ms})$ and in comparison to the adjacent native cartilage less zonal organization. $\mathrm{T} 2{ }^{*}$ maps were reconstructed using a multiecho gradient echo (GRE) acquisition, with a TR of $600 \mathrm{~ms}$ and 6 TEs of $4.2,11.3,18.5,25.6,32,7$, and $39.9 \mathrm{~ms}$. The field of view was $160 \times 160 \mathrm{~mm}$, the pixel matrix was $384 \times 384$, and the voxel size was $0.4 \times 0.4 \times 3.0 \mathrm{~mm}$. The bandwidth was $260 \mathrm{~Hz} /$ pixel, with 12 slices; total acquisition time was 2:35 minutes.

tissue and normal cartilage [166]. Using a GRE T2* approach with the same ${ }^{*}{ }^{*}$ sequence, Welsch et al. found 2.3 years after MACI a comparable $\mathrm{T} 2$ between repair tissue and normal cartilage but a lower $\mathrm{T}^{*}{ }^{*}$ in repair tissue. Zonal stratification was also more pronounced for $\mathrm{T} 2 *$ than for $\mathrm{T} 2$ [84]. This might be due to the influence of local susceptibility variations on $\mathrm{T} 2{ }^{*}$, at the macroscopic level, that is, associated with the bone/cartilage interface or at the microscopic level, that is, associated with the underlying microstructure of the cartilage. For Mfx, comparable to MSME T2 mapping, no spatial variation was observed for cartilage repair tissue after Mfx using T2* mapping [83]. At 7 T, T2 and T2* mapping was applicable, but with overall lower relaxation times and a reduced zonal (laminar) appearance of articular cartilage $[72,167]$.

At the talus, ACI repair tissue showed normal T2 values in a 5-year and in a 10-year followup $[168,169]$. Repair tissue showed comparable T2 values to hyaline cartilage 2 years and 4 years after bone marrow derived cell transplantation at the talus [170, 171]. T2 differed significantly between the superficial and deep layers 9.5 years after Mfx, detected via 7 T MRI [141].

3.2.2. Cartilage Repair Findings for T1rho Relaxation Time Measurements. First efforts have been made to apply T1rho relaxation times for assessment of cartilage repair tissue [139, 140, 172]. A differentiation between different tissue types after cartilage repair procedures was possible by applying T1rho mapping, in particular, in combination with T2 mapping [139]. To date, T1rho has been applied to imaging of repair tissue after Mfx and OAT (Figure 3).
Holtzman et al. reported that cartilage repair tissue after OAT showed slightly higher T1rho values than normal surrounding cartilage at 3 to 6 months and at 1 year after surgery [139]. On the contrary, T2 values were not significantly different between repair cartilage and normal cartilage. There was no difference found for T1rho and T2 values between the time points 3 to 6 months and 1 year [139].

After Mfx, Holtzman et al. observed significantly higher T1rho (and T2) values for cartilage repair tissue as compared to surrounding cartilage tissue 3 to 6 months after surgery [139]. Also Theologis et al. reported that T1rho values of cartilage repair tissue after Mfx remained higher than normal cartilage after 1 year as opposed to T2 values [140]. Laminar analysis showed significantly higher T1rho for both, the deep and the superficial layer 3-6 months after Mfx [139]. At 1-year followup, T1rho values of the deep layer decreased, indicating a maturation regarding PG content [140].

3.2.3. Cartilage Repair Findings for dGEMRIC Measurements. dGEMRIC measurements correlate with cartilage degeneration and may predict the development of OA due to their sensitivity for GAG content of hyaline cartilage [20, 21]. dGEMRIC is increasingly applied to assess cartilage repair tissue. Watanabe et al. reported that dGEMRIC measurements correlated with GAG content of ACI grafts [119]. Few studies analyzed OAT and Mfx using dGEMRIC. T1-Gd values of OAT were comparable to normal cartilage, about 1 and 2 years after surgery with a normal zonal stratification $[126,173]$. Significantly different relative delta relaxation times were found for Mfx and MACI, suggesting a lower PG content of the repair tissue after Mfx as compared to MACI (Figure 4) [165].

There are more studies analyzing repair tissue after ACI $[39,63,69,124,125,132,165,174-176]$. Higher delta relaxation rates and lower T1-Gd values, indicating lower GAG contents, were reported for repair tissue than for normal cartilage at baseline and 1 year, 3-13 months, and 9-42 months after MACI $[35,102]$. On the other hand, T1-Gd values were comparable to normal cartilage 10-15 months and 2-24 months after surgery. Several studies found significant differences of dGEMRIC values between $<1$ year of followup and later time points after MACI, correlating with improving GAG contents [106, 110, 124]. However, Trattnig et al. reported that T1-Gd was lower in repair tissue than in normal cartilage 2.8 and 4.7 years after MACI [23, 165]. About 4 and 5 years after MACI, a stable T1-Gd was observed by Brix et al. [175]. T1-Gd was not significantly different between repair tissue and normal cartilage 9 to 18 years after ACI according to Vasiliadis et al. [177]. Laminar analysis of dGEMRIC measurements did not show a significant difference between superficial or deep tissue as compared to the control cartilage 1 year after ACI [125]. Pinker et al. detected a tendency toward an increase in global and zonal GAG content in the deep zone of the transplant after 1 year [35].

dGEMRIC was also applied for postoperative assessment after MACI at the ankle. Domayer et al. reported no significant difference between the delta relaxation rates in repair tissue and normal cartilage [117]. Wiewiorski et al. found 

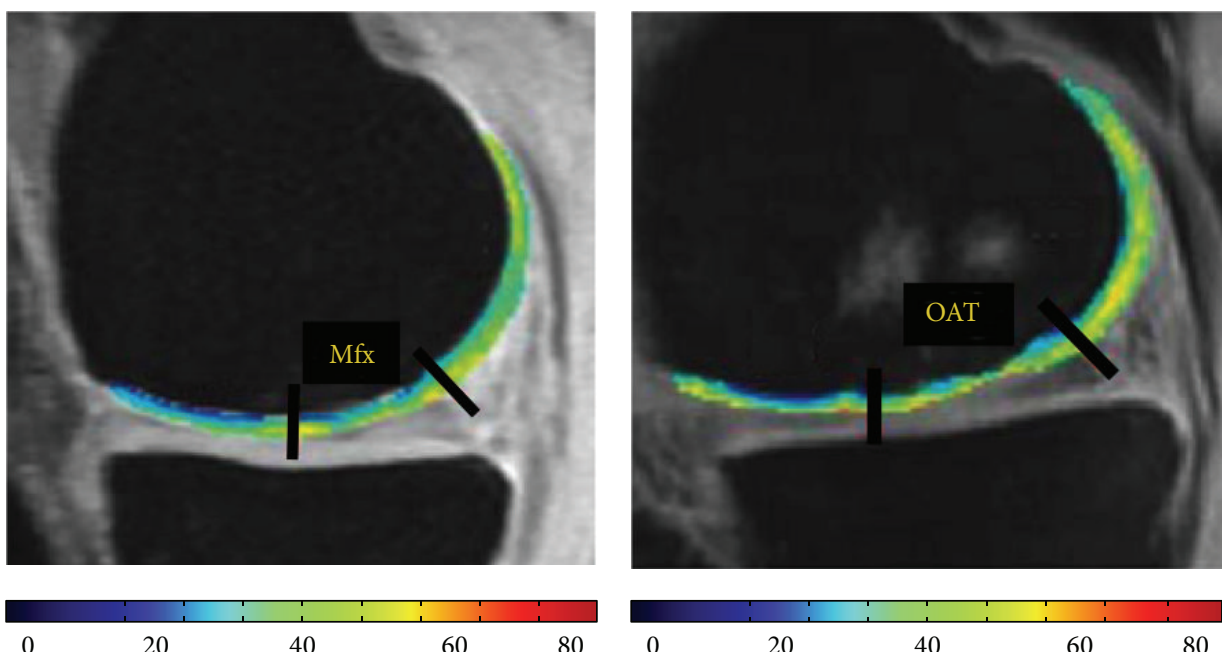

FIgURE 3: Left figure: T1rho-microfracture (Mfx). Quantitative T1rho mapping at the knee 1 year after Mfx of the medial femoral condyle. At the 1 year followup, the cartilage repair tissue still showed elevated T1 rho values as compared to surrounding cartilage. Right figure: T1rhoOAT. Quantitative T1rho map after OAT therapy of the medial femoral condyle. The cartilage repair tissue showed slightly higher T1rho values than normal surrounding cartilage. T1rho images were acquired using spin-lock techniques and 3D SPGR acquisition. TR was $9.3 \mathrm{~ms}$. TE was $3.7 \mathrm{~ms}$. The field of view was $140 \times 140 \mathrm{~mm}$. The pixel matrix was $256 \times 192$. The slice thickness was $3 \mathrm{~mm}$. The bandwidth was $31.25 \mathrm{kHz}$. The views per segment (VPS) were 48 . The time of recovery (Trec) was $1.5 \mathrm{~s}$. The time of spin lock (TSL) was $0,10,40$, and $80 \mathrm{~ms}$ and the spin-lock frequency (FSL) was $500 \mathrm{~Hz}$.
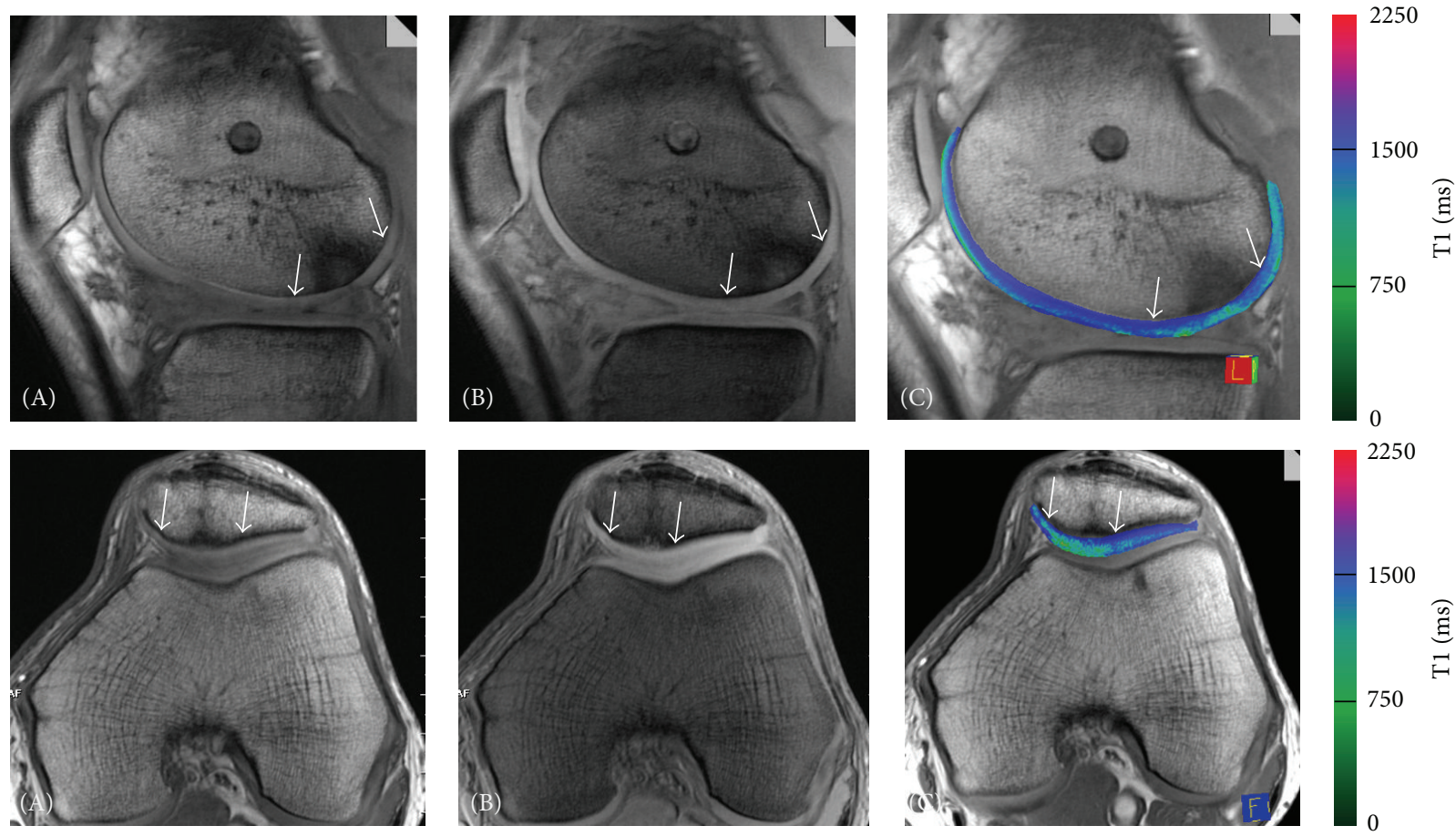

FIGURE 4: Upper row: dGEMRIC-MACI. Delayed gadolinium-enhanced MRI of cartilage (dGEMRIC) of a 39-year-old male patient 24 months after MACI of the lateral femoral condyle (marked by arrows). Images (A) and (B) represent the raw images with the different flip angles on which the dGEMRIC-T1 map is based (C). The T1-dGEMRIC map shows slightly reduced GAG content in the repair tissue. Lower row: dGEMRIC-MFX. Delayed gadolinium-enhanced MRI of cartilage (dGEMRIC) of a 42-year-old male patient 24 months after microfracture therapy of the patella cartilage (marked by arrows). Images (A) and (B) represent the raw images with the different flip angles on which the dGEMRIC-T1 map is based (C). The T1-dGEMRIC map showed a clearly reduced GAG content in the repair tissue. For T1-Gd mapping, we used a 3D gradient echo (GRE) sequence with a TR of $15 \mathrm{~ms}$, a TE of $1.95 \mathrm{~ms}$, and two flip angles of $5^{\circ}$ and $18.6^{\circ}$. The field of view was $160 \times 160 \mathrm{~mm}$, the pixel matrix was $384 \times 384$, and the voxel size was $0.4 \times 0.4 \times 3.0 \mathrm{~mm}$; the bandwidth was $480 \mathrm{~Hz} /$ pixel and $22 \mathrm{slices}$ were assessed with a total acquisition time of 3:40 minutes. 


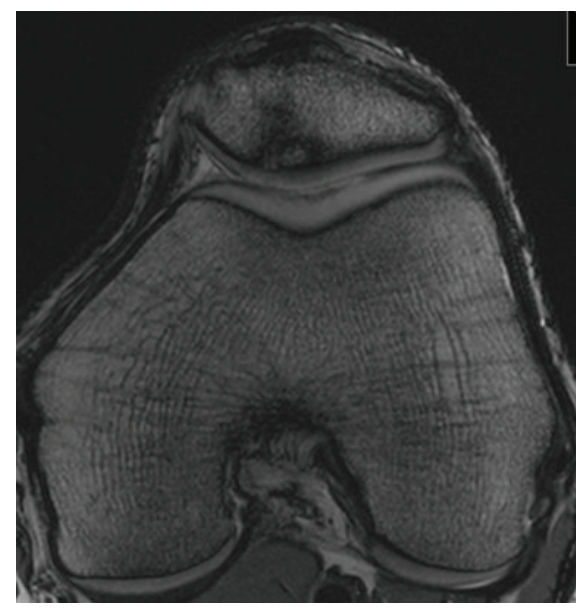

(a)

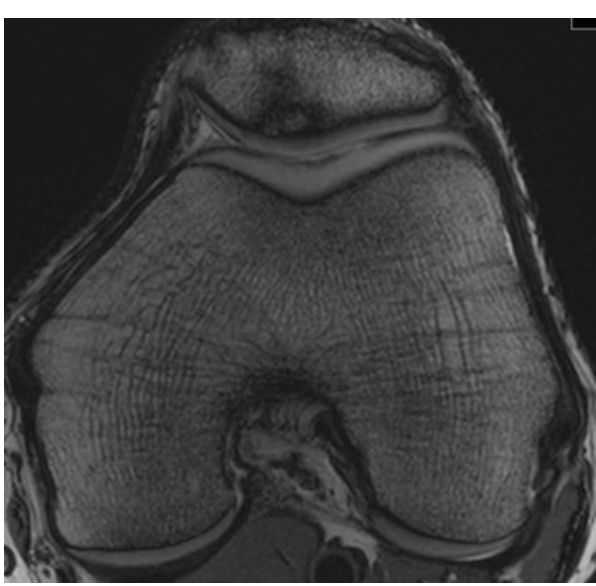

(c)

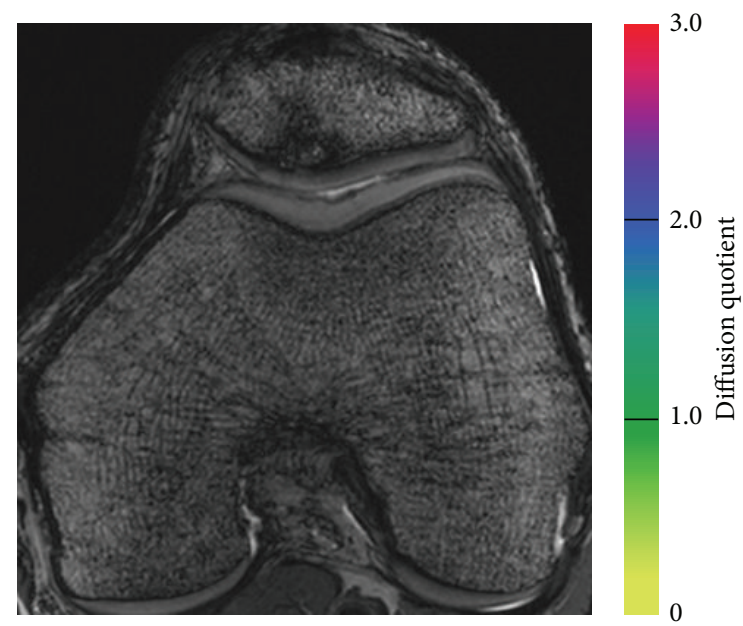

(b)

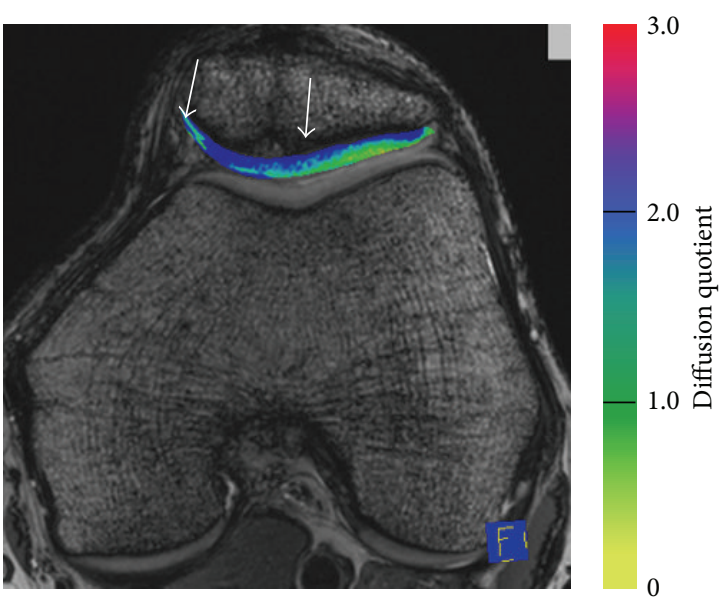

(d)

FiguRE 5: Diffusion weighted imaging (DWI) of a 42-year-old male patient 24 months after microfracture therapy of the patella cartilage (marked by arrows). Images (a) and (b) represent the raw images of two different diffusion directions, whereas image (c) is the reversed FISP sequence without any diffusion quotient. As visualized in the diffusion map (d), the diffusivity was clearly increased in the cartilage repair tissue compared to the surrounding cartilage. DWI maps were reconstructed using a three-dimensional, balanced, steady-state gradient echo pulse sequence with diffusion weighting (3D DWPSIF) (reversed FISP = fast imaging with steady-state precession), with a TR of $16.3 \mathrm{~ms}$ and TEs of $6.1 \mathrm{~ms}$. The field of view was $160 \times 160 \mathrm{~mm}$, the pixel matrix was $384 \times 384$, and the voxel size was $0.4 \times 0.4 \times 3.0 \mathrm{~mm}$, with 3 slices (through the area of cartilage repair); total acquisition time was 6:48 minutes.

significantly higher delta T1 values for MACI at the talus than for normal cartilage [52].

3.2.4. Cartilage Repair Findings for Diffusion Imaging. Diffusion imaging may provide additional information for evaluation of cartilage repair tissue (Figure 5) [32, 62, 131, $132,178]$. DWI distinguished healthy cartilage from cartilage repair tissue in Mfx and MACI 2.7 years after surgery [132]. Mamisch et al. reported that diffusion in repair cartilage after MACI was significantly higher than in normal cartilage. There was a decrease between the earlier and the later time point after surgery [178]. Also, Friedrich et al. [131] found that after MACI, in a group with the first exam less than 13 months after surgery and a 1-year follow-up exam, diffusion quotients were significantly lower at the followup. In a group with the first exam more than 13 months after MACI and a 1-year follow-up exam no statistically significant differences in diffusivity were found between the two time points. This may reflect cartilage maturation [131].

After MACI at the ankle joint cartilage repair tissue showed no significant difference in $\mathrm{T} 2$ and $\mathrm{T} 2{ }^{*}$ relaxation times compared to the control cartilage, but it showed a higher diffusivity [179]. Apprich et al. examined cartilage repair at the ankle 5 years after Mfx and 4 years after MACI using DWI [180]. Diffusivity was similar between normal cartilage and MACI; however, Mfx repair tissue showed significantly different DWI values compared to both, MACI and normal cartilage [180]. 
3.2.5. Correlations of Different Biomarkers. Since GAG depletion generally occurs before collagen disruption, cartilage imaging techniques with sensitivity for different pathological mechanisms may detect not only different stages of cartilage degeneration but also different stages of cartilage repair [85, 181]. Further, different techniques may have different dynamic ranges such as T1rho and T2 [181] or dGEMRIC and T2 [107]. Therefore, it seems likely that, besides morphological imaging and clinical scores, a multimodal approach combining different quantitative MR imaging techniques may enable a more comprehensive characterization of cartilage repair [125]. A multimodal approach was already performed by several study groups that analyzed cartilage repair $[72,83,107$, $125,132,139,140,179]$. Nevertheless, more cross-validation of different MR imaging methods needs to be performed in future studies. This is especially important to gain more information on the use, the meaning, and the significance of the different techniques in assessing cartilage and cartilage repair tissue.

3.2.6. Correlation with Morphological and Clinical Scores. Several studies have evaluated the correlation of MR cartilage biomarkers with clinical scores. For the majority of quantitative MRI parameters, limited or no correlation was reported. A correlation between Lysholm scores and T2 was found by Welsch et al., Krusche-Mandl et al., and Domeyer et al. [26, $132,155]$. Giannini et al. found a correlation of T2 maps with clinical results after bone marrow derived cell transplantation at the talus [171]. Welsch et al. found a correlation of Lysholm scores and DWI [132]. Bekkers et al. found a similar improvement of clinical scores and dGEMRIC measurements from baseline to a 12-month followup [106]. Two systematic metaanalyses were recently published analyzing the correlation of MRI parameters with clinical outcome $[37,46]$. A correlation between clinical outcome and MOCART or Henderson score was found in only nine studies $(28 \%)[37,46]$. The authors reported a weak to moderate correlation between clinical outcome and T2 [37]. Overall, de Wind et al. stated that strong evidence to determine whether morphological MRI is reliable in predicting clinical outcome after cartilage repair is lacking [37].

Regarding morphological MR scores, significant correlations were found between MOCART score and DWI after Mfx and MACI $[132,180]$. Most authors however stated that quantitative MR imaging did not correlate significantly with morphological MR scores [132, 178].

\section{Discussion}

Based on findings in early cartilage degeneration, focal cartilage defects, and OA, quantitative MR imaging may be helpful for assessing biochemical composition and maturation of cartilage repair tissue, its ultrastructural outcome and intraindividual quality. To date, most studies involved ACI, although studies investigated OAT and Mfx. For all biomarkers, studies reported that a difference of quantitative values for repair tissue after Mfx compared with ACI or OAT could be detected. Most studies were performed at the knee; few studies were performed at the ankle. The latter showed more inconsistent results that additionally differed from those at the knee.

At the knee, T2 relaxation time measurements, which are sensitive to collagen disruption, seem to be the most established quantitative imaging techniques so far. Summarizing the findings of the different studies, T2 values for OAT were initially similar to normal cartilage but increased years after surgery. For Mfx, initially elevated T2 values were found that decreased to values similar to normal cartilage about 1 to 2 years after surgery and decreased further during longer followup. Mfx did not show a zonal stratification. Mfx generally showed lower T2 values than ACI. ACI also presented elevated $\mathrm{T} 2$ values initially that decreased to normal values during the second year after surgery. However, also after ACI, a further decrease of $\mathrm{T} 2$ values during longer followup of up to 5 years after surgery was observed. Zonal stratification appeared during the second year after surgery and persisted during longer followup. T2 mapping was frequently used in combination with PG sensitive techniques such as dGEMRIC or T1rho, thus providing complementary information. This underlines the importance of combining several quantitative MR imaging techniques, alongside with morphological and clinical evaluation for postoperative followup and monitoring after cartilage repair procedures for most conclusive tissue assessment.

T1rho was found to be elevated in cartilage repair tissue after OAT and Mfx as compared to normal cartilage up to 1 year after surgery. No longer followup was performed so far. For T1rho mapping, high SL fields are desirable, since it correlates positively with T1rho relaxation times. However, due to long durations of the SL pulse, some groups reported high SAR as a major issue for clinical application and therefore suggested limited clinical use of T1rho [7, 120, 182]. This SAR issue seems even more important at $3 \mathrm{~T}$ as compared to 1.5 T. However, other groups could optimize these sequences while staying within the prescribed SAR limits. Further, it was reported that T1rho was not entirely GAG specific [94].

Regarding dGEMRIC, results of current studies are more heterogeneous than for T2. For Mfx, less PG content was detected by dGEMRIC than for ACI. OAT showed normal PG content and a normal zonal stratification. Most studies were performed on ACI. In some studies, PG content, detected by dGEMRIC, was lower in repair tissue 1-3 and about 3 and 5 years after ACI. Other studies reported values comparable to normal cartilage during not only the first 2 years but also 918 years after surgery, as well as stable PG contents between 4 and 5 years after ACI. These diverging results may have different explanations, such as different surgical techniques, different imaging protocols, different coils, different time points of contrast agent administration, different analysis methods, and different patient cohorts. The main disadvantage of dGEMRIC is the relatively long examination time and the requirement of exogenous gadolinium-based contrast agent injection with its rare but possible side effects of nephrogenic systemic fibrosis and allergic reactions. Therefore, it has to be stated clearly that in future approaches comparable quantitative analyses may be possible without contrast injections. Further, a static state with complete equilibration after contrast agent injection cannot be reached in vivo and the 
GAG content of the deep cartilage layer may be overestimated [183-185]. Further, dGEMRIC may not be specific to GAG. No study has evaluated the dependency of dGEMRIC values from the intra-articular contrast concentration so far.

For DWI, the current studies mainly describe a higher diffusivity for cartilage repair tissue after MACI as compared to normal cartilage with a decrease over time. After about 2 years, DWI values remained stable. Using current routine techniques, it seems difficult to obtain precise measures of the diffusion values in cartilage, due to image distortions, limitations in contrast, and sensitivity to motion artifacts [131]. Ongoing approaches on more stable and clinical feasible sequences (e.g., SSFP approach) try to enable for quantitative DWI in cartilage and cartilage repair. Clinical application of DTI is challenging due to long acquisition times, high field strengths, and intensive data analysis.

Currently, clinical correlations are limited and clinical importance including prediction of procedure outcome needs to be demonstrated in larger cross-sectional and longitudinal cohort studies. Standards of reference have to be established in dependence on follow-up time points in long-term followup after different cartilage repair procedures. Quantitative MR imaging did rarely correlate significantly with morphological MR scores and may possibly provide supplemental information for evaluation of cartilage transplant maturation $[132,178]$.

To date, all quantitative imaging techniques have several technical and methodological limitations and therefore remain work-in-progress. For all sequences, manual segmentation is required which is limited by inter- and intraobserver reliability errors. To date, the difficult and time-consuming segmentation process may be one of the most important issues, which limits the broad clinical use of quantitative MR techniques. No entirely automated segmentation tool is available so far. Driven by different companies and working groups, this problem may be solved in the future, aiming for the immediate availability of quantitative values after MR acquisition.

Frequently, the surrounding cartilage has been considered as normal cartilage and was used as a reference standard for calculation of an index; however, the adjacent cartilage cannot in general be considered as healthy $[39,124,186$, 187]. Surrounding cartilage showed further deterioration after cartilage repair. This may be one explanation for the lack of correlation between morphological and biochemical MRI and clinical score. For this reason, there are upcoming approaches that consider the entire joint cartilage after cartilage repair. Looking only at the repair tissue area itself may not be representative for the entire joint. [188]. A general standard of reference for each MR biomarker is still lacking and difficult to obtain, since different acquisition methods, calibration procedures, coils, and MR scanners lead to varying results. Further, only in case of OAT, it is known that the transplant initially consists of hyaline cartilage. For ACI and Mfx, quantitative values may detect any tissue that accidentally shows quantitative values comparable to hyaline cartilage. "Normal" tissue multimodal characteristics would need to be defined for each specific tissue. It appears doubtful that quantitative imaging characteristics that were obtained in hyaline cartilage can directly be transferred to repair tissue with an unpredictable histological composition. Characterization of cartilage repair tissue by using only one imaging parameter seems unlikely. One important step would be to combine different biomarkers in a multimodal approach to gain the most conclusive information on the tissue characteristics. At the current time point, it seems challenging that all quantitative imaging techniques may be performed at once due to the long acquisition times.

\section{Conclusions}

In conclusion, noninvasive quantitative $\mathrm{MR}$ imaging of cartilage repair tissue has shown varying results. Multiple imaging biomarkers such as T2 mapping, T1rho, and dGEMRIC demonstrated sensitivity to biochemical alterations of cartilage repair tissue. However, results that were obtained in hyaline cartilage do not seem to be easily transmittable to repair tissue. While quantitative MR biomarkers are established for $\mathrm{OA}$ for cartilage repair purposes, all techniques remain work-in-progress. Acquiring accurate and clinically valuable quantitative data has proven challenging. Considering the limitations, using multimodal approaches including multiple quantitative MR biomarkers, morphological MRI, and clinical scores in combination would be most promising for clinical applications in the future.

\section{Conflict of Interests}

All authors declare that there is no conflict of interests regarding the publication of this paper.

\section{Acknowledgments}

This work was supported by the German Research Foundation (DFG) and the Technische Universitaet Muenchen within the funding programme Open Access Publishing.

\section{References}

[1] R. K. Surowiec, E. P. Lucas, and C. P. Ho, "Quantitative MRI in the evaluation of articular cartilage health: reproducibility and variability with a focus on $\mathrm{T}_{2}$ mapping," Knee Surgery, Sports Traumatology, Arthroscopy, 2013.

[2] D. A. Binks, R. J. Hodgson, M. E. Ries et al., "Quantitative parametric MRI of articular cartilage: a review of progress and open challenges," The British Journal of Radiology, vol. 86, no. 1023, Article ID 20120163, 2013.

[3] L. M. Jazrawi, M. J. Alaia, G. Chang, E. F. FitzGerald, and M. P. Recht, "Advances in magnetic resonance imaging of articular cartilage," Journal of the American Academy of Orthopaedic Surgeons, vol. 19, no. 7, pp. 420-429, 2011.

[4] T. M. Link, R. Stahl, and K. Woertler, "Cartilage imaging: motivation, techniques, current and future significance," European Radiology, vol. 17, no. 5, pp. 1135-1146, 2007.

[5] D. J. Hunter, W. Zhang, P. G. Conaghan et al., "Systematic review of the concurrent and predictive validity of MRI biomarkers in OA," Osteoarthritis and Cartilage, vol. 19, no. 5, pp. 557-588, 2011.

[6] D. Burstein, M. Gray, T. Mosher, and B. Dardzinski, "Measures of molecular composition and structure in osteoarthritis," 
Radiologic Clinics of North America, vol. 47, no. 4, pp. 675-686, 2009.

[7] A. Borthakur, E. Mellon, S. Niyogi, W. Witschey, J. B. Kneeland, and R. Reddy, "Sodium and $\mathrm{T}_{1 \rho}$ MRI for molecular and diagnostic imaging of articular cartilage," NMR in Biomedicine, vol. 19, no. 7, pp. 781-821, 2006.

[8] A. R. Poole, T. Kojima, T. Yasuda, F. Mwale, M. Kobayashi, and S. Laverty, "Composition and structure of articular cartilage: a template for tissue repair," Clinical Orthopaedics and Related Research, no. 391, supplement, pp. S26-S33, 2001.

[9] L. C. Dijkgraaf, L. G. M. de Bont, G. Boering, and R. S. B. Liem, "Normal cartilage structure, biochemistry, and metabolism: a review of the literature," Journal of Oral and Maxillofacial Surgery, vol. 53, no. 8, pp. 924-929, 1995.

[10] E. Lammentausta, P. Kiviranta, M. J. Nissi et al., " $\mathrm{T}_{2}$ relaxation time and delayed gadolinium-enhanced MRI of cartilage (dGEMRIC) of human patellar cartilage at $1.5 \mathrm{~T}$ and $9.4 \mathrm{~T}$ : relationships with tissue mechanical properties," Journal of Orthopaedic Research, vol. 24, no. 3, pp. 366-374, 2006.

[11] M. J. Nissi, J. Töyräs, M. S. Laasanen et al., "Proteoglycan and collagen sensitive MRI evaluation of normal and degenerated articular cartilage," Journal of Orthopaedic Research, vol. 22, no. 3, pp. 557-564, 2004.

[12] T. Mendlik, S. C. Faber, J. Weber et al., "T $T_{2}$ quantitation of human articular cartilage in a clinical setting at $1.5 \mathrm{~T}$ : implementation and testing of four multiecho pulse sequence designs for validity," Investigative Radiology, vol. 39, no. 5, pp. 288-299, 2004.

[13] M. F. Koff, K. K. Amrami, J. P. Felmlee, and K. R. Kaufman, "Bias of cartilage $\mathrm{T}_{2}$ values related to method of calculation," Magnetic Resonance Imaging, vol. 26, no. 9, pp. 1236-1243, 2008.

[14] M. D. Crema, F. W. Roemer, M. D. Marra et al., "Articular cartilage in the knee: current MR imaging techniques and applications in clinical practice and research," Radiographics, vol. 31, no. 1, pp. 37-61, 2011.

[15] F. Eckstein, W. Wirth, and M. C. Nevitt, "Recent advances in osteoarthritis imaging-the osteoarthritis initiative," Nature Reviews Rheumatology, vol. 8, no. 10, pp. 622-630, 2012.

[16] H. E. Smith, T. J. Mosher, B. J. Dardzinski et al., "Spatial variation in cartilage $\mathrm{T}_{2}$ of the knee," Journal of Magnetic Resonance Imaging, vol. 14, no. 1, pp. 50-55, 2001.

[17] B. J. Dardzinski, T. J. Mosher, S. Li, M. A. van Slyke, and M. B. Smith, "Spatial variation of $\mathrm{T}_{2}$ in human articular cartilage," Radiology, vol. 205, no. 2, pp. 546-550, 1997.

[18] T. J. Mosher, B. J. Dardzinski, and M. B. Smith, "Human articular cartilage: influence of aging and early symptomatic degeneration on the spatial variation of $\mathrm{T}_{2}$ - preliminary findings at $3 \mathrm{~T}$," Radiology, vol. 214, no. 1, pp. 259-266, 2000.

[19] A. Bashir, M. L. Gray, and D. Burstein, "Gd-DTPA ${ }^{2-}$ as a measure of cartilage degradation," Magnetic Resonance in Medicine, vol. 36 , no. 5, pp. 665-673, 1996.

[20] H. Owman, C. J. Tiderius, P. Neuman, F. Nyquist, and L. E. Dahlberg, "Association between findings on delayed gadolinium-enhanced magnetic resonance imaging of cartilage and future knee osteoarthritis," Arthritis \& Rheumatism, vol. 58, no. 6, pp. 1727-1730, 2008.

[21] A. Williams, L. Sharma, C. A. McKenzie, P. V. Prasad, and D. Burstein, "Delayed gadolinium-enhanced magnetic resonance imaging of cartilage in knee osteoarthritis: findings at different radiographic stages of disease and relationship to malalignment," Arthritis \& Rheumatism, vol. 52, no. 11, pp. 3528-3535, 2005.
[22] R. Reddy, E. K. Insko, E. A. Noyszewski, R. Dandora, J. B. Kneeland, and J. S. Leigh, "Sodium MRI of human articular cartilage in vivo," Magnetic Resonance in Medicine, vol. 39, no. 5, pp. 697-701, 1998.

[23] S. Trattnig, G. H. Welsch, V. Juras et al., "23 Na MR imaging at $7 \mathrm{~T}$ after knee matrix-associated autologous chondrocyte transplantation preliminary results," Radiology, vol. 257, no. 1, pp. 175-184, 2010.

[24] M. L. Gray, D. Burstein, K. Y. Kim, and A. Maroudas, "2007 Elizabeth Winston Lanier Award Winner. Magnetic resonance imaging of cartilage glycosaminoglycan: basic principles, imaging technique, and clinical applications," Journal of Orthopaedic Research, vol. 26, no. 3, pp. 281-291, 2008.

[25] W. Ling, R. R. Regatte, G. Navon, and A. Jerschow, "Assessment of glycosaminoglycan concentration in vivo by chemical exchange-dependent saturation transfer (gagCEST)," Proceedings of the National Academy of Sciences of the United States of America, vol. 105, no. 7, pp. 2266-2270, 2008.

[26] I. Krusche-Mandl, B. Schmitt, L. Zak et al., "Long-term results 8 years after autologous osteochondral transplantation: $7 \mathrm{~T}$ gagCEST and sodium magnetic resonance imaging with morphological and clinical correlation," Osteoarthritis and Cartilage, vol. 20, no. 5, pp. 357-363, 2012.

[27] B. Schmitt, Š. Zbýň, D. Stelzeneder et al., "Cartilage quality assessment by using glycosaminoglycan chemical exchange saturation transfer and ${ }^{23} \mathrm{Na} \mathrm{MR}$ imaging at $7 \mathrm{~T}$,' Radiology, vol. 260, no. 1, pp. 257-264, 2011.

[28] A. Singh, M. Haris, K. Cai et al., "Chemical exchange saturation transfer magnetic resonance imaging of human knee cartilage at $3 \mathrm{~T}$ and 7 T," Magnetic Resonance in Medicine, vol. 68, no. 2, pp. 588-594, 2012.

[29] R. R. Regatte, S. V. S. Akella, A. Borthakur, J. B. Kneeland, and $\mathrm{R}$. Reddy, "In vivo proton $\mathrm{MR}$ three-dimensional $\mathrm{T}_{1 \rho}$ mapping of human articular cartilage: initial experience," Radiology, vol. 229, no. 1, pp. 269-274, 2003.

[30] R. R. Regatte, S. V. S. Akella, A. Borthakur, and R. Reddy, "Proton spin-lock ratio imaging for quantitation of glycosaminoglycans in articular cartilage," Journal of Magnetic Resonance Imaging, vol. 17, no. 1, pp. 114-121, 2003.

[31] X. Li, E. T. Han, C. B. Ma, T. M. Link, D. C. Newitt, and S. Majumdar, "In vivo $3 \mathrm{~T}$ spiral imaging based multi-slice $\mathrm{T}_{1 \rho}$ mapping of knee cartilage in osteoarthritis," Magnetic Resonance in Medicine, vol. 54, no. 4, pp. 929-936, 2005.

[32] V. Mlynarik, I. Sulzbacher, M. Bittšanský, R. Fuiko, and S. Trattnig, "Investigation of apparent diffusion constant as an indicator of early degenerative disease in articular cartilage," Journal of Magnetic Resonance Imaging, vol. 17, no. 4, pp. 440444, 2003.

[33] L. Filidoro, O. Dietrich, J. Weber et al., "High-resolution diffusion tensor imaging of human patellar cartilage: feasibility and preliminary findings," Magnetic Resonance in Medicine, vol. 53, no. 5, pp. 993-998, 2005.

[34] J. Carballido-Gamio, G. B. Joseph, J. A. Lynch, T. M. Link, and S. Majumdar, "Longitudinal analysis of MRI T 2 knee cartilage laminar organization in a subset of patients from the osteoarthritis initiative: a texture approach," Magnetic Resonance in Medicine, vol. 65, no. 4, pp. 1184-1194, 2011.

[35] K. Pinker, P. Szomolanyi, G. C. Welsch et al., "Longitudinal evaluation of cartilage composition of matrix-associated autologous chondrocyte transplants with 3-T delayed gadoliniumenhanced MRI of cartilage," American Journal of Roentgenology, vol. 191, no. 5, pp. 1391-1396, 2008. 
[36] H. G. Potter and L. F. Foo, "Magnetic resonance imaging of articular cartilage: trauma, degeneration, and repair," The American Journal of Sports Medicine, vol. 34, no. 4, pp. 661-677, 2006.

[37] T. S. de Windt, G. H. Welsch, M. Brittberg et al., "Is magnetic resonance imaging reliable in predicting clinical outcome after articular cartilage repair of the knee? A systematic review and meta-analysis," The American Journal of Sports Medicine, vol. 41, no. 7, pp. 1695-1702, 2013.

[38] G. Chang, O. Sherman, G. Madelin, M. Recht, and R. Regatte, "MR imaging assessment of articular cartilage repair procedures," Magnetic Resonance Imaging Clinics of North America, vol. 19, no. 2, pp. 323-337, 2011.

[39] M. T. Nieminen, M. J. Nissi, L. Matteila, and I. Kiviranta, "Evaluation of chondral repair using quantitative MRI," Journal of Magnetic Resonance Imaging, vol. 36, no. 6, pp. 1287-1299, 2012.

[40] D. D. Frisbie, J. T. Oxford, L. Southwood et al., "Early events in cartilage repair after subchondral bone microfracture," Clinical Orthopaedics and Related Research, no. 407, pp. 215-227, 2003.

[41] F. Shapiro, S. Koide, and M. J. Glimcher, "Cell origin and differentiation in the repair of full-thickness defects of articular cartilage," The Journal of Bone \& Joint Surgery Series A, vol. 75, no. 4, pp. 532-553, 1993.

[42] M. Steinwachs and P. C. Kreuz, "Autologous chondrocyte implantation in chondral defects of the knee with a type I/III collagen membrane: a prospective study with a 3-year followup," Arthroscopy, vol. 23, no. 4, pp. 381-387, 2007.

[43] L. Hangody, P. Feczkó, L. Bartha, G. Bodó, and G. Kish, "Mosaicplasty for the treatment of articular defects of the knee and ankle," Clinical Orthopaedics and Related Research, no. 391, supplement, pp. S328-S336, 2001.

[44] S. Marlovits, P. Singer, P. Zeller, I. Mandl, J. Haller, and S. Trattnig, "Magnetic resonance observation of cartilage repair tissue (MOCART) for the evaluation of autologous chondrocyte transplantation: determination of interobserver variability and correlation to clinical outcome after 2 years," European Journal of Radiology, vol. 57, no. 1, pp. 16-23, 2006.

[45] G. H. Welsch, L. Zak, T. C. Mamisch, C. Resinger, S. Marlovits, and S. Trattnig, "Three-dimensional magnetic resonance observation of cartilage repair tissue (MOCART) score assessed with an isotropic three-dimensional true fast imaging with steadystate precession sequence at 3.0 Tesla," Investigative radiology, vol. 44, no. 9, pp. 603-612, 2009.

[46] A. J. Blackman, M. V. Smith, D. C. Flanigan, M. J. Matava, R. W. Wright, and R. H. Brophy, "Correlation between magnetic resonance imaging and clinical outcomes after cartilage repair surgery in the knee: a systematic review and meta-analysis," The American Journal of Sports Medicine, vol. 41, no. 6, pp. 14261434, 2013.

[47] P. C. Kreuz, S. Müller, A. von Keudell et al., "Influence of sex on the outcome of autologous chondrocyte implantation in chondral defects of the knee," The American Journal of Sports Medicine, vol. 41, no. 7, pp. 1541-1548, 2013.

[48] S. Zbyn, D. Stelzened, G. H. Welsch et al., "Evaluation of native hyaline cartilage and repair tissue after two cartilage repair surgery techniques with ${ }^{23} \mathrm{Na} \mathrm{MR}$ imaging at $7 \mathrm{~T}$ : initial experience," Osteoarthritis and Cartilage, vol. 20, no. 8, pp. 837845, 2012.

[49] T. Baum, G. B. Joseph, D. C. Karampinos, P. M. Jungmann, T. M. Link, and J. S. Bauer, "Cartilage and meniscal $\mathrm{T}_{2}$ relaxation time as non-invasive biomarker for knee osteoarthritis and cartilage repair procedures," Osteoarthritis and Cartilage, vol. 21, no. 10, pp. 1474-1484, 2013.
[50] W. E. Brown, H. G. Potter, R. G. Marx, T. L. Wickiewicz, and R. F. Warren, "Magnetic resonance imaging appearance of cartilage repair in the knee," Clinical Orthopaedics and Related Research, no. 422, pp. 214-223, 2004.

[51] S. Trattnig, S. Zbýň, B. Schmitt et al., "Advanced MR methods at ultra-high field (7 Tesla) for clinical musculoskeletal applications," European Radiology, vol. 22, no. 11, pp. 2338-2346, 2012.

[52] M. Wiewiorski, M. Miska, M. Kretzschmar, U. Studler, O. Bien, and V. Valderrabano, "Delayed gadolinium-enhanced MRI of cartilage of the ankle joint: results after autologous matrix-induced chondrogenesis (AMIC)-aided reconstruction of osteochondral lesions of the talus," Clinical Radiology, vol. 68, no. 10, pp. 1031-1038, 2013.

[53] G. Chang, A. Horng, and C. Glaser, "A practical guide to imaging of cartilage repair with emphasis on bone marrow changes," Seminars in Musculoskeletal Radiology, vol. 15, no. 3, pp. 221-237, 2011.

[54] Y. S. Choi, H. G. Potter, and T. J. Chun, "MR imaging of cartilage repair in the knee and ankle," Radiographics, vol. 28, no. 4, pp. 1043-1059, 2008.

[55] S. E. Domayer, G. H. Welsch, R. Dorotka et al., "MRI monitoring of cartilage repair in the knee: a review," Seminars in Musculoskeletal Radiology, vol. 12, no. 4, pp. 302-317, 2008.

[56] R. Gnannt, A. Chhabra, J. S. Theodoropoulos, J. Hodler, and G. Andreisek, "MR imaging of the postoperative knee," Journal of Magnetic Resonance Imaging, vol. 34, no. 5, pp. 1007-1021, 2011.

[57] C. Hayter and H. Potter, "Magnetic resonance imaging of cartilage repair techniques," The Journal of Knee Surgery, vol. 24, no. 4, pp. 225-240, 2011.

[58] R. J. Hughes and D. G. Houlihan-Burne, "Clinical and MRI considerations in sports-related knee joint cartilage injury and cartilage repair," Seminars in Musculoskeletal Radiology, vol. 15, no. 1, pp. 69-88, 2011.

[59] S. L. James, D. A. Connell, A. Saifuddin, J. A. Skinner, and T. W. R. Briggs, "MR imaging of autologous chondrocyte implantation of the knee," European Radiology, vol. 16, no. 5, pp. 10221030, 2006.

[60] J. Polster and M. Recht, "Postoperative MR evaluation of chondral repair in the knee," European Journal of Radiology, vol. 54, no. 2, pp. 206-213, 2005.

[61] H. G. Potter, R. C. Le, and D. B. Sneag, "Magnetic resonance imaging of cartilage repair," Sports Medicine and Arthroscopy Review, vol. 16, no. 4, pp. 236-245, 2008.

[62] S. Trattnig, S. Domayer, G. W. Welsch, T. Mosher, and F. Eckstein, "MR imaging of cartilage and its repair in the knee-a review," European Radiology, vol. 19, no. 7, pp. 1582-1594, 2009.

[63] S. Trattnig, S. A. Millington, P. Szomolanyi, and S. Marlovits, "MR imaging of osteochondral grafts and autologous chondrocyte implantation," European Radiology, vol. 17, no. 1, pp. 103118, 2007.

[64] I. Y. Tsou, M. Yegappan, W. S. Ong, P. O. L. Goh, J. L. Tan, and T. S. G. Chee, "Cartilage injury and repair: assessment with magnetic resonance imaging," Singapore Medical Journal, vol. 47, no. 1, pp. 80-88, 2006.

[65] K. L. Verstraete, F. Almqvist, P. Verdonk et al., "Magnetic resonance imaging of cartilage and cartilage repair," Clinical Radiology, vol. 59, no. 8, pp. 674-689, 2004.

[66] G. H. Welsch, T. C. Mamisch, L. Zak et al., "Morphological and biochemical $\mathrm{T}_{2}$ evaluation of cartilage repair tissue based on a hybrid double echo at steady state (DESS- $\mathrm{T}_{2} \mathrm{~d}$ ) approach," Journal of Magnetic Resonance Imaging, vol. 34, no. 4, pp. 895903, 2011. 
[67] R. A. Gallo and T. J. Mosher, "Imaging of cartilage and osteochondral injuries: a case-based review," Clinics in Sports Medicine, vol. 32, no. 3, pp. 477-505, 2013.

[68] V. M. Ho-Fung and D. Jaramillo, "Cartilage imaging in children: current indications, magnetic resonance imaging techniques, and imaging findings," Radiologic Clinics of North America, vol. 51, no. 4, pp. 689-702, 2013.

[69] H. G. Potter, B. R. Black, and R. C. Le, "New techniques in articular cartilage imaging," Clinics in Sports Medicine, vol. 28, no. 1, pp. 77-94, 2009.

[70] C. E. Quatman, C. M. Hettrich, L. C. Schmitt, and K. P. Spindler, "The clinical utility and diagnostic performance of magnetic resonance imaging for identification of early and advanced knee osteoarthritis: a systematic review," The American Journal of Sports Medicine, vol. 39, no. 7, pp. 1557-1568, 2011.

[71] M. P. Recht, D. W. Goodwin, C. S. Winalski, and L. M. White, "MRI of articular cartilage: revisiting current status and future directions," American Journal of Roentgenology, vol. 185, no. 4, pp. 899-914, 2005.

[72] G. H. Welsch, T. C. Mamisch, T. Hughes et al., "In vivo biochemical 7.0 Tesla magnetic resonance: preliminary results of dGEMRIC, zonal $\mathrm{T}_{2}$, and $\mathrm{T}_{2}^{*}$ mapping of articular cartilage," Investigative Radiology, vol. 43, no. 9, pp. 619-626, 2008.

[73] M. E. Mayerhoefer, G. H. Welsch, T. C. Mamisch et al., "The in vivo effects of unloading and compression on $\mathrm{T}_{1}$-Gd (dGEMRIC) relaxation times in healthy articular knee cartilage at 3.0 Tesla," European Radiology, vol. 20, no. 2, pp. 443-449, 2010.

[74] M. L. Pachowsky, S. Trattnig, B. Wondrasch et al., "In vivo evaluation of biomechanical properties in the patellofemoral joint after matrix-associated autologous chondrocyte transplantation by means of quantitative $\mathrm{T}_{2}$ MRI," Knee Surgery, Sports Traumatology, Arthroscopy, 2013.

[75] T. C. Mamisch, S. Trattnig, S. Quirbach, S. Marlovits, L. M. White, and G. H. Welsch, "Quantitative $\mathrm{T}_{2}$ mapping of knee cartilage: differentiation of healthy control cartilage and cartilage repair tissue in the knee with unloading-initial results," Radiology, vol. 254, no. 3, pp. 818-826, 2010.

[76] G. B. Joseph, T. Baum, H. Alizai et al., "Baseline mean and heterogeneity of MR cartilage $T_{2}$ are associated with morphologic degeneration of cartilage, meniscus, and bone marrow over 3 years-data from the Osteoarthritis Initiative," Osteoarthritis and Cartilage, vol. 20, no. 7, pp. 727-735, 2012.

[77] A. Pai, X. Li, and S. Majumdar, "A comparative study at $3 \mathrm{~T}$ of sequence dependence of $\mathrm{T}_{2}$ quantitation in the knee," Magnetic Resonance Imaging, vol. 26, no. 9, pp. 1215-1220, 2008.

[78] Y. Xia, "Magic-angle effect in magnetic resonance imaging of articular cartilage: a review," Investigative Radiology, vol. 35, no. 10, pp. 602-621, 2000.

[79] A. Watanabe, C. Boesch, T. Obata, and S. E. Anderson, "Effect of multislice acquisition on $\mathrm{T}_{1}$ and $\mathrm{T}_{2}$ measurements of articular cartilage at 3 T,' Journal of Magnetic Resonance Imaging, vol. 26, no. 1, pp. 109-117, 2007.

[80] C. G. Peterfy, E. Schneider, and M. Nevitt, “The osteoarthritis initiative: report on the design rationale for the magnetic resonance imaging protocol for the knee," Osteoarthritis and Cartilage, vol. 16, no. 12, pp. 1433-1441, 2008.

[81] J. Du, A. M. Takahashi, and C. B. Chung, "Ultrashort TE spectroscopic imaging (UTESI): application to the imaging of short $\mathrm{T}_{2}$ relaxation tissues in the musculoskeletal system," Journal of Magnetic Resonance Imaging, vol. 29, no. 2, pp. 412-421, 2009.
[82] A. Williams, Y. Qian, D. Bear, and C. R. Chu, "Assessing degeneration of human articular cartilage with ultra-short echo time (UTE) $T_{2}{ }^{*}$ mapping," Osteoarthritis and Cartilage, vol. 18, no. 4, pp. 539-546, 2010.

[83] T. C. Mamisch, T. Hughes, T. J. Mosher et al., " $\mathrm{T}_{2}$ star relaxation times for assessment of articular cartilage at $3 \mathrm{~T}$ : a feasibility study," Skeletal Radiology, vol. 41, no. 3, pp. 287-292, 2012.

[84] G. H. Welsch, S. Trattnig, T. Hughes et al., " $\mathrm{T}_{2}$ and $\mathrm{T}_{2}^{*}$ mapping in patients after matrix-associated autologous chondrocyte transplantation: initial results on clinical use with 3.0-Tesla MRI," European Radiology, vol. 20, no. 6, pp. 1515-1523, 2010.

[85] X. Li, C. Benjamin Ma, T. M. Link et al., "In vivo $\mathrm{T}_{1 \rho}$ and $T_{2}$ mapping of articular cartilage in osteoarthritis of the knee using 3 T MRI," Osteoarthritis and Cartilage, vol. 15, no. 7, pp. 789-797, 2007.

[86] R. E. Sepponen, J. A. Pohjonen, J. T. Sipponen, and J. I. Tanttu, "A method for $\mathrm{T}_{1 \rho}$ imaging," Journal of Computer Assisted Tomography, vol. 9, no. 6, pp. 1007-1011, 1985.

[87] R. R. Regatte, S. V. S. Akella, A. J. Wheaton, A. Borthakur, J. B. Kneeland, and R. Reddy, " $\mathrm{T}_{1 \rho}$-relaxation mapping of human femoral-tibial cartilage in vivo," Journal of Magnetic Resonance Imaging, vol. 18, no. 3, pp. 336-341, 2003.

[88] A. G. Redfield, "Nuclear spin thermodynamics in the rotating frame," Science, vol. 164, no. 3883, pp. 1015-1023, 1969.

[89] U. Duvvuri, R. Reddy, S. D. Patel, J. H. Kaufman, J. B. Kneeland, and J. S. Leigh, " $\mathrm{T}_{1}$-relaxation in articular cartilage: effects of enzymatic degradation," Magnetic Resonance in Medicine, vol. 38, no. 6, pp. 863-867, 1997.

[90] S. V. Akella, R. R. Regatte, A. J. Gougoutas et al., "Proteoglycaninduced changes in $\mathrm{T}_{1 \rho}$-relaxation of articular cartilage at $4 \mathrm{~T}$," Magnetic Resonance in Medicine, vol. 46, no. 3, pp. 419-423, 2001.

[91] C. Taylor, J. Carballido-Gamio, S. Majumdar, and X. Li, “Comparison of quantitative imaging of cartilage for osteoarthritis: $\mathrm{T}_{2}, \mathrm{~T}_{1 \rho}$, dGEMRIC and contrast-enhanced computed tomography," Magnetic Resonance Imaging, vol. 27, no. 6, pp. 779-784, 2009.

[92] W. R. Witschey, A. Borthakur, M. Fenty et al., "T $T_{1 \rho}$ MRI quantification of arthroscopically confirmed cartilage degeneration," Magnetic Resonance in Medicine, vol. 63, no. 5, pp. 1376-1382, 2010.

[93] R. R. Regatte, S. V. S. Akella, A. J. Wheaton et al., "3D-T $1 \rho-$-relaxation mapping of articular cartilage: in vivo assessment of early degenerative changes in symptomatic osteoarthritic subjects," Academic Radiology, vol. 11, no. 7, pp. 741-749, 2004.

[94] V. Mlynarik, S. Trattnig, M. Huber, A. Zembsch, and H. Imhof, "The role of relaxation times in monitoring proteoglycan depletion in articular cartilage," Journal of Magnetic Resonance Imaging, vol. 10, no. 4, pp. 497-502, 1999.

[95] A. Borthakur, J. Hulvershorn, E. Gualtieri et al., "A pulse sequence for rapid in vivo spin-locked MRI," Journal of Magnetic Resonance Imaging, vol. 23, no. 4, pp. 591-596, 2006.

[96] W. R. Witschey, A. Borthakur, M. A. Sochor et al., “T $1 \rho$-prepared balanced gradient echo for rapid $3 \mathrm{D} \mathrm{T}_{1 \rho}$ MRI," Journal of Magnetic Resonance Imaging, vol. 28, no. 3, pp. 744-754, 2008.

[97] Y.-J. Kim, D. Jaramillo, M. B. Millis, M. L. Gray, and D. Burstein, "Assessment of early osteoarthritis in hip dysplasia with delayed gadolinium-enhanced magnetic resonance imaging of cartilage," The Journal of Bone \& Joint Surgery Series A, vol. 85, no. 10, pp. 1987-1992, 2003. 
[98] A. Bashir, M. L. Gray, J. Hartke, and D. Burstein, "Nondestructive imaging of human cartilage glycosaminoglycan concentration by MRI," Magnetic Resonance in Medicine, vol. 41, no. 5, pp. 857-865, 1999.

[99] D. Burstein, J. Velyvis, K. T. Scott et al., "Protocol issues for delayed Gd(DTPA) ${ }^{2-}$-enhanced MRI (dGEMRIC) for clinical evaluation of articular cartilage," Magnetic Resonance in Medicine, vol. 45, no. 1, pp. 36-41, 2001.

[100] C. J. Tiderius, L. E. Olsson, P. Leander, O. Ekberg, and L. Dahlberg, "Delayed gadolinium-enhanced MRI of cartilage (dGEMRIC) in early knee osteoarthritis," Magnetic Resonance in Medicine, vol. 49, no. 3, pp. 488-492, 2003.

[101] E. M. Roos and L. Dahlberg, "Positive effects of moderate exercise on glycosaminoglycan content in knee cartilage: a fourmonth, randomized, controlled trial in patients at risk of osteoarthritis," Arthritis \& Rheumatism, vol. 52, no. 11, pp. 3507-3514, 2005.

[102] S. Trattnig, S. Marlovits, S. Gebetsroither et al., “Three-dimensional delayed gadolinium-enhanced MRI of cartilage (dGEMRIC) for in vivo evaluation of reparative cartilage after matrixassociated autologous chondrocyte transplantation at $3.0 \mathrm{~T}$ : preliminary results," Journal of Magnetic Resonance Imaging, vol. 26, no. 4, pp. 974-982, 2007.

[103] M. T. Nieminen, N. M. Menezes, A. Williams, and D. Burstein, " $T_{2}$ of articular cartilage in the presence of Gd-DTPA ${ }^{2-}$, " Magnetic Resonance in Medicine, vol. 51, no. 6, pp. 1147-1152, 2004.

[104] S. Trattnig, V. Mlyńarik, M. Breitenseher et al., "MRI visualization of proteoglycan depletion in articular cartilage via intravenous administration of Gd-DTPA," Magnetic Resonance Imaging, vol. 17, no. 4, pp. 577-583, 1999.

[105] A. Bashir, M. L. Gray, R. D. Boutin, and D. Burstein, "Glycosaminoglycan in articular cartilage: in vivo assessment with delayed Gd(DTPA) ${ }^{2-}$-enhanced MR imaging," Radiology, vol. 205, no. 2, pp. 551-558, 1997.

[106] J. E. Bekkers, L. W. Bartels, R. J. Benink et al., "Delayed gadolinium enhanced MRI of cartilage (dGEMRIC) can be effectively applied for longitudinal cohort evaluation of articular cartilage regeneration," Osteoarthritis and Cartilage, vol. 21, no. 7, pp. 943-949, 2013.

[107] S. E. Domayer, G. H. Welsch, S. Nehrer et al., " $T_{2}$ mapping and dGEMRIC after autologous chondrocyte implantation with a fibrin-based scaffold in the knee: preliminary results," European Journal of Radiology, vol. 73, no. 3, pp. 636-642, 2010.

[108] T. C. Mamisch, M. Dudda, T. Hughes, D. Burstein, and Y.-J. Kim, "Comparison of delayed gadolinium enhanced MRI of cartilage (dGEMRIC) using inversion recovery and fast $\mathrm{T}_{1}$ mapping sequences," Magnetic Resonance in Medicine, vol. 60, no. 4, pp. 768-773, 2008.

[109] A. Watanabe, C. Boesch, S. E. Anderson, W. Brehm, and P. Mainil Varlet, "Ability of dGEMRIC and $\mathrm{T}_{2}$ mapping to evaluate cartilage repair after microfracture: a goat study," Osteoarthritis and Cartilage, vol. 17, no. 10, pp. 1341-1349, 2009.

[110] S. Trattnig, D. Burstein, P. Szomolanyi, K. Pinker, G. H. Welsch, and T. C. Mamisch, " $\mathrm{T}_{1}(\mathrm{Gd})$ gives comparable information as Delta $\mathrm{T}_{1}$ relaxation rate in dGEMRIC evaluation of cartilage repair tissue," Investigative radiology, vol. 44, no. 9, pp. 598-602, 2009.

[111] C. Zilkens, F. Miese, B. Bittersohl et al., "Delayed gadoliniumenhanced magnetic resonance imaging of cartilage (dGEMRIC), after slipped capital femoral epiphysis," European Journal of Radiology, vol. 79, no. 3, pp. 400-406, 2011.
[112] C. A. McKenzie, A. Williams, P. V. Prasad, and D. Burstein, "Three-dimensional delayed gadolinium-enhanced MRI of cartilage (dGEMRIC) at 1.5 T and 3.0 T,' Journal of Magnetic Resonance Imaging, vol. 24, no. 4, pp. 928-933, 2006.

[113] S. Sur, T. C. Mamisch, T. Hughes, and Y.-J. Kim, "High resolution fast $\mathrm{T}_{1}$ mapping technique for dGEMRIC," Journal of Magnetic Resonance Imaging, vol. 30, no. 4, pp. 896-900, 2009.

[114] T. Kimelman, A. Vu, P. Storey, C. McKenzie, D. Burstein, and P. Prasad, "Three-dimensional $\mathrm{T}_{1}$ mapping for dGEMRIC at 3.0 T using the look locker method," Investigative Radiology, vol. 41, no. 2, pp. 198-203, 2006.

[115] C. J. Tiderius, L. E. Olsson, H. De Verdier, P. Leander, O. Ekberg, and L. Dahlberg, "Gd-DTPA ${ }^{2-}$-enhanced MRI of femoral knee cartilage: a dose-response study in healthy volunteers," Magnetic Resonance in Medicine, vol. 46, no. 6, pp. 1067-1071, 2001.

[116] T. S. Silvast, H. T. Kokkonen, J. S. Jurvelin, T. M. Quinn, M. T. Nieminen, and J. Töyräs, "Diffusion and near-equilibrium distribution of MRI and CT contrast agents in articular cartilage," Physics in Medicine and Biology, vol. 54, no. 22, pp. 6823-6836, 2009.

[117] S. E. Domayer, S. Trattnig, D. Stelzeneder et al., "Delayed gadolinium-enhanced MRI of cartilage in the ankle at $3 \mathrm{~T}$ : feasibility and preliminary results after matrix-associated autologous chondrocyte implantation," Journal of Magnetic Resonance Imaging, vol. 31, no. 3, pp. 732-739, 2010.

[118] R. L. Mauck, C. T. Hung, and G. A. Ateshian, "Modeling of neutral solute transport in a dynamically loaded porous permeable gel: implications for articular cartilage biosynthesis and tissue engineering," Journal of Biomechanical Engineering, vol. 125, no. 5, pp. 602-614, 2003.

[119] A. Watanabe, Y. Wada, T. Obata et al., "Delayed gadoliniumenhanced MR to determine glycosaminoglycan concentration in reparative cartilage after autologous chondrocyte implantation: preliminary results," Radiology, vol. 239, no. 1, pp. 201-208, 2006.

[120] D. Burstein and M. L. Gray, "Is MRI fulfilling its promise for molecular imaging of cartilage in arthritis?" Osteoarthritis and Cartilage, vol. 14, no. 11, pp. 1087-1090, 2006.

[121] A. Williams, B. Mikulis, N. Krishnan, M. Gray, C. McKenzie, and D. Burstein, "Suitability of $T_{1 \mathrm{Gd}}$ as the "dGEMRIC index" at 1.5 T and 3.0 T," Magnetic Resonance in Medicine, vol. 58, no. 4, pp. 830-834, 2007.

[122] W. Li, H. Du, R. Scheidegger, Y. Wu, and P. V. Prasad, "Value of precontrast $\mathrm{T}_{1}$ for dGEMRIC of native articular cartilage," Journal of Magnetic Resonance Imaging, vol. 29, no. 2, pp. 494497, 2009.

[123] B. Bittersohl, H. S. Hosalkar, Y.-J. Kim, S. Werlen, K. A. Siebenrock, and T. C. Mamisch, "Delayed gadolinium-enhanced magnetic resonance imaging (dGEMRIC) of hip joint cartilage in femoroacetabular impingement (FAI): are pre- and postcontrast imaging both necessary?" Magnetic Resonance in Medicine, vol. 62, no. 6, pp. 1362-1367, 2009.

[124] A. Gillis, A. Bashir, B. McKeon, A. Scheller, M. L. Gray, and D. Burstein, "Magnetic resonance imaging of relative glycosaminoglycan distribution in patients with autologous chondrocyte transplants," Investigative Radiology, vol. 36, no. 12, pp. 743$748,2001$.

[125] J. E. Kurkijarvi, L. Mattila, R. O. Ojala et al., "Evaluation of cartilage repair in the distal femur after autologous chondrocyte transplantation using $T_{2}$ relaxation time and dGEMRIC," Osteoarthritis and Cartilage, vol. 15, no. 4, pp. 372-378, 2007. 
[126] M. G. Durkan, J. Szumowski, D. S. Brown, E. W. Foss, and D. C. Crawford, "In vivo MRI of fresh stored osteochondral allograft transplantation with delayed gadolinium-enhanced MRI of cartilage: protocol considerations and recommendations," Magnetic Resonance in Medicine, vol. 69, no. 6, pp. 1745-1753, 2013.

[127] D. M. Pierce, W. Trobin, J. G. Raya et al., "DT-MRI based computation of collagen fiber deformation in human articular cartilage: a feasibility study," Annals of Biomedical Engineering, vol. 38, no. 7, pp. 2447-2463, 2010.

[128] D. Burstein, M. L. Gray, A. L. Hartman, R. Gipe, and B. D. Foy, "Diffusion of small solutes in cartilage as measured by nuclear magnetic resonance (NMR) spectroscopy and imaging," Journal of Orthopaedic Research, vol. 11, no. 4, pp. 465-478, 1993.

[129] K. L. Miller, B. A. Hargreaves, G. E. Gold, and J. M. Pauly, "Steady-state diffusion-weighted imaging of in vivo knee cartilage," Magnetic Resonance in Medicine, vol. 51, no. 2, pp. 394398, 2004.

[130] P. J. Basser, J. Mattiello, and D. Lebihan, "Estimation of the effective self-diffusion tensor from the NMR spin echo," Journal of Magnetic Resonance Series B, vol. 103, no. 3, pp. 247-254, 1994.

[131] K. M. Friedrich, T. C. Mamisch, C. Plank et al., "Diffusionweighted imaging for the follow-up of patients after matrixassociated autologous chondrocyte transplantation," European Journal of Radiology, vol. 73, no. 3, pp. 622-628, 2010.

[132] G. H. Welsch, S. Trattnig, S. Domayer, S. Marlovits, L. M. White, and T. C. Mamisch, "Multimodal approach in the use of clinical scoring, morphological MRI and biochemical $\mathrm{T}_{2}$-mapping and diffusion-weighted imaging in their ability to assess differences between cartilage repair tissue after microfracture therapy and matrix-associated autologous chondrocyte transplantation: a pilot study," Osteoarthritis and Cartilage, vol. 17, no. 9, pp. 12191227, 2009.

[133] O. Bieri, C. Ganter, and K. Scheffler, "Quantitative in vivo diffusion imaging of cartilage using double echo steady-state free precession," Magnetic Resonance in Medicine, vol. 68, no. 3, pp. 720-729, 2012.

[134] A. M. Heemskerk, G. J. Strijkers, A. Vilanova, M. R. Drost, and K. Nicolay, "Determination of mouse skeletal muscle architecture using three-dimensional diffusion tensor imaging," Magnetic Resonance in Medicine, vol. 53, no. 6, pp. 1333-1340, 2005.

[135] R. Meder, S. K. de Visser, J. C. Bowden, T. Bostrom, and J. M. Pope, "Diffusion tensor imaging of articular cartilage as a measure of tissue microstructure," Osteoarthritis and Cartilage, vol. 14, no. 9, pp. 875-881, 2006.

[136] J. G. Raya, G. Melkus, S. Adam-Neumair et al., "Diffusion-tensor imaging of human articular cartilage specimens with early signs of cartilage damage," Radiology, vol. 266, no. 3, pp. 831-841, 2013.

[137] X. Deng, M. Farley, M. T. Nieminen, M. Gray, and D. Burstein, "Diffusion tensor imaging of native and degenerated human articular cartilage," Magnetic Resonance Imaging, vol. 25, no. 2, pp. 168-171, 2007.

[138] S. K. de Visser, R. W. Crawford, and J. M. Pope, "Structural adaptations in compressed articular cartilage measured by diffusion tensor imaging," Osteoarthritis and Cartilage, vol. 16, no. 1, pp. 83-89, 2008.

[139] D. J. Holtzman, A. A. Theologis, J. Carballido-Gamio, S. Majumdar, X. Li, and C. Benjamin, " $\mathrm{T}_{1 \rho}$ and $\mathrm{T}_{2}$ quantitative magnetic resonance imaging analysis of cartilage regeneration following microfracture and mosaicplasty cartilage resurfacing procedures," Journal of Magnetic Resonance Imaging, vol. 32, no. 4, pp. 914-923, 2010.
[140] A. A. Theologis, W. W. Schairer, J. Carballido-Gamio, S. Majumdar, X. Li, and C. B. Ma, "Longitudinal analysis of $\mathrm{T}_{1 \rho}$ and $\mathrm{T}_{2}$ quantitative MRI of knee cartilage laminar organization following microfracture surgery," The Knee, vol. 19, no. 5, pp. 652-657, 2012.

[141] S. E. Domayer, S. Apprich, D. Stelzender et al., "Cartilage repair of the ankle: first results of $\mathrm{T}_{2}$ mapping at 7.0 $\mathrm{T}$ after microfracture and matrix associated autologous cartilage transplantation," Osteoarthritis and Cartilage, vol. 20, no. 8, pp. 829-836, 2012.

[142] L. M. White, M. S. Sussman, M. Hurtig, L. Probyn, G. Tomlinson, and R. Kandel, "Cartilage $\mathrm{T}_{2}$ assessment: differentiation of normal hyaline cartilage and reparative tissue after arthroscopic cartilage repair in equine subjects," Radiology, vol. 241, no. 2, pp. 407-414, 2006.

[143] A. Watrin-Pinzano, J.-P. Ruaud, P. Olivier et al., "Effect of proteoglycan depletion on $\mathrm{T}_{2}$ mapping in rat patellar cartilage," Radiology, vol. 234, no. 1, pp. 162-170, 2005.

[144] G. H. Welsch, T. C. Mamisch, S. E. Domayer et al., "Cartilage $T_{2}$ assessment at 3-T MR imaging: in vivo differentiation of normal hyaline cartilage from reparative tissue after two cartilage repair procedures-initial experience," Radiology, vol. 247, no. 1, pp. 154-161, 2008.

[145] G. H. Welsch, T. C. Mamisch, S. Marlovits et al., "Quantitative $\mathrm{T}_{2}$ mapping during follow-up after matrix-associated autologous chondrocyte transplantation (MACT): full-thickness and zonal evaluation to visualize the maturation of cartilage repair tissue," Journal of Orthopaedic Research, vol. 27, no. 7, pp. 957963, 2009.

[146] G. Knutsen, J. O. Drogset, L. Engebretsen et al., "A randomized trial comparing autologous chondrocyte implantation with microfracture: findings at five years," The Journal of Bone \& Joint Surgery Series A, vol. 89, no. 10, pp. 2105-2112, 2007.

[147] G. Knutsen, V. Isaksen, O. Johansen et al., "Autologous chondrocyte implantation compared with microfracture in the knee," The Journal of Bone \& Joint Surgery Series A, vol. 86, no. 3, pp. 455-464, 2004.

[148] R. Gudas, R. J. Kalesinskas, V. Kimtys et al., "A prospective randomized clinical study of mosaic osteochondral autologous transplantation versus microfracture for the treatment of osteochondral defects in the knee joint in young athletes," Arthroscopy, vol. 21, no. 9, pp. 1066-1075, 2005.

[149] M. H. Zheng, C. Willers, L. Kirilak et al., "Matrix-induced autologous chondrocyte implantation (MACI): biological and histological assessment," Tissue Engineering, vol. 13, no. 4, pp. 737-746, 2007.

[150] S. Nehrer and T. Minas, "Treatment of articular cartilage defects," Investigative Radiology, vol. 35, no. 10, pp. 639-646, 2000.

[151] B. J. Tins, I. W. McCall, T. Takahashi et al., "Autologous chondrocyte implantation in knee joint: MR imaging and histologic features at 1-year follow-up," Radiology, vol. 234, no. 2, pp. 501508, 2005.

[152] T. Minas and S. Nehrer, "Current concepts in the treatment of articular cartilage defects," Orthopedics, vol. 20, no. 6, pp. 525538, 1997.

[153] S. C. Ghivizzani, T. J. Oligino, P. D. Robbins, and C. H. Evans, "Cartilage injury and repair," Physical Medicine and Rehabilitation Clinics of North America, vol. 11, no. 2, pp. 289-307, 2000 . 
[154] T. R. McCauley and D. G. Disler, "Magnetic resonance imaging of articular cartilage of the knee," The Journal of the American Academy of Orthopaedic Surgeons, vol. 9, no. 1, pp. 2-8, 2001.

[155] S. E. Domayer, F. Kutscha-Lissberg, G. Welsch et al., " $\mathrm{T}_{2}$ mapping in the knee after microfracture at $3.0 \mathrm{~T}$ : correlation of global $\mathrm{T}_{2}$ values and clinical outcome-preliminary results," Osteoarthritis and Cartilage, vol. 16, no. 8, pp. 903-908, 2008.

[156] G. H. Welsch, T. C. Mamisch, S. Quirbach, L. Zak, S. Marlovits, and S. Trattnig, "Evaluation and comparison of cartilage repair tissue of the patella and medial femoral condyle by using morphological MRI and biochemical zonal $\mathrm{T}_{2}$ mapping," European Radiology, vol. 19, no. 5, pp. 1253-1262, 2009.

[157] G. H. Welsch, T. C. Mamisch, L. Zak et al., "Evaluation of cartilage repair tissue after matrix-associated autologous chondrocyte transplantation using a hyaluronic-based or a collagenbased scaffold with morphological MOCART scoring and biochemical $\mathrm{T}_{2}$ mapping: preliminary results," The American Journal of Sports Medicine, vol. 38, no. 5, pp. 934-942, 2010.

[158] W. D. Stanish, R. McCormack, F. Forriol et al., "Novel scaffoldbased BST-CarGel treatment results in superior cartilage repair compared with microfracture in a randomized controlled trial," The Journal of Bone \& Joint Surgery Series A, vol. 95, no. 18, pp. 1640-1650, 2013.

[159] S. Apprich, G. H. Welsch, T. C. Mamisch et al., "Detection of degenerative cartilage disease: comparison of high-resolution morphological MR and quantitative $\mathrm{T}_{2}$ mapping at 3.0 Tesla," Osteoarthritis and Cartilage, vol. 18, no. 9, pp. 1211-1217, 2010.

[160] G. M. Salzmann, J. Paul, J. S. Bauer et al., " $\mathrm{T}_{2}$ assessment and clinical outcome following autologous matrix-assisted chondrocyte and osteochondral autograft transplantation," Osteoarthritis and Cartilage, vol. 17, no. 12, pp. 1576-1582, 2009.

[161] J. M. Oneto, J. Ellermann, and R. F. LaPrade, "Longitudinal evaluation of cartilage repair tissue after microfracture using $\mathrm{T}_{2}$ mapping: a case report with arthroscopic and MRI correlation," Knee Surgery, Sports Traumatology, Arthroscopy, vol. 18, no. 11, pp. 1545-1550, 2010.

[162] G. H. Welsch, S. Trattnig, K. Scheffler et al., "Magnetization transfer contrast and $\mathrm{T}_{2}$ mapping in the evaluation of cartilage repair tissue with $3 \mathrm{~T}$ MRI," Journal of Magnetic Resonance Imaging, vol. 28, no. 4, pp. 979-986, 2008.

[163] S. Trattnig, T. C. Mamisch, G. H. Welsch et al., "Quantitative $T_{2}$ mapping of matrix-associated autologous chondrocyte transplantation at 3 Tesla: an in vivo cross-sectional study," Investigative Radiology, vol. 42, no. 6, pp. 442-448, 2007.

[164] I. Eshed, S. Trattnig, M. Sharon et al., "Assessment of cartilage repair after chondrocyte transplantation with a fibrin-hyaluronan matrix - correlation of morphological MRI, biochemical $\mathrm{T}_{2}$ mapping and clinical outcome," European Journal of Radiology, vol. 81, no. 6, pp. 1216-1223, 2012.

[165] S. Trattnig, T. C. Mamisch, K. Pinker et al., "Differentiating normal hyaline cartilage from post-surgical repair tissue using fast gradient echo imaging in delayed gadolinium-enhanced MRI (dGEMRIC) at 3 Tesla," European Radiology, vol. 18, no. 6, pp. 1251-1259, 2008.

[166] D. Stelzeneder, A. A. Shetty, S.-J. Kim et al., "Repair tissue quality after arthroscopic autologous collagen-induced chondrogenesis (ACIC) assessed via $\mathrm{T}_{2}^{*}$ mapping," Skeletal Radiology, vol. 42, no. 12, pp. 1657-1664, 2013.

[167] G. Chang, D. Xia, O. Sherman et al., "High resolution morphologic imaging and $\mathrm{T}_{2}$ mapping of cartilage at 7 Tesla: comparison of cartilage repair patients and healthy controls,"
Magnetic Resonance Materials in Physics, Biology and Medicine, vol. 26, no. 6, pp. 539-548, 2013.

[168] M. Battaglia, F. Vannini, R. Buda et al., "Arthroscopic autologous chondrocyte implantation in osteochondral lesions of the talus: mid-term $\mathrm{T}_{2}$-mapping MRI evaluation," Knee Surgery, Sports Traumatology, Arthroscopy, vol. 19, no. 8, pp. 1376-1384, 2011.

[169] S. Giannini, M. Battaglia, R. Buda, M. Cavallo, A. Ruffilli, and F. Vannini, "Surgical treatment of osteochondral lesions of the talus by open-field autologous chondrocyte implantation: a 10year follow-up clinical and magnetic resonance imaging $\mathrm{T}_{2}$ mapping evaluation," The American Journal of Sports Medicine, vol. 37, supplement 1, pp. 112S-118S, 2009.

[170] M. Battaglia, E. Rimondi, C. Monti et al., "Validity of $\mathrm{T}_{2}$ mapping in characterization of the regeneration tissue by bone marrow derived cell transplantation in osteochondral lesions of the ankle," European Journal of Radiology, vol. 80, no. 2, pp. el32-e139, 2011.

[171] S. Giannini, R. Buda, M. Battaglia et al., "One-step repair in talar osteochondral lesions: 4-year clinical results and $\mathrm{T}_{2}$-mapping capability in outcome prediction," The American Journal of Sports Medicine, vol. 41, no. 3, pp. 511-518, 2013.

[172] P. M. Jungmann, X. Li, L. Nardo et al., "Do cartilage repair procedures prevent degenerative meniscus changes?: longitudinal $\mathrm{T}_{1 \rho}$ and morphological evaluation with 3.0-T MRI," The American Journal of Sports Medicine, vol. 40, no. 12, pp. 2700-2708, 2012.

[173] J. E. Bekkers, L. W. Bartels, K. L. Vincken et al., "Articular cartilage evaluation after TruFit plug implantation analyzed by delayed gadolinium-enhanced MRI of cartilage (dGEMRIC)," The American Journal of Sports Medicine, vol. 41, no. 6, pp. 1290 1295, 2013.

[174] G. H. Welsch, T. C. Mamisch, T. Hughes, S. Domayer, S. Marlovits, and S. Trattnig, "Advanced morphological and biochemical magnetic resonance imaging of cartilage repair procedures in the knee joint at 3 Tesla," Seminars in Musculoskeletal Radiology, vol. 12, no. 3, pp. 196-211, 2008.

[175] M. O. Brix, D. Stelzeneder, S. Trattnig, R. Windhanger, and S. E. Domayer, "Cartilage repair of the knee with Hyalograft C: Magnetic Resonance Imaging assessment of the glycosaminoglycan content at midterm," International Orthopaedics, vol. 37, no. 1, pp. 39-43, 2013.

[176] C. J. Tiderius, L. E. Olsson, F. Nyquist, and L. Dahlberg, "Cartilage glycosaminoglycan loss in the acute phase after an anterior cruciate ligament injury: delayed gadolinium-enhanced magnetic resonance imaging of cartilage and synovial fluid analysis," Arthritis \& Rheumatism, vol. 52, no. 1, pp. 120-127, 2005.

[177] H. S. Vasiliadis, B. Danielson, M. Ljungberg, B. McKeon, A. Lindahl, and L. Peterson, "Autologous chondrocyte implantation in cartilage lesions of the knee: long-term evaluation with magnetic resonance imaging and delayed gadolinium-enhanced magnetic resonance imaging technique," The American Journal of Sports Medicine, vol. 38, no. 5, pp. 943-949, 2010.

[178] T. C. Mamisch, M. I. Menzel, G. H. Welsch et al., "Steadystate diffusion imaging for MR in-vivo evaluation of reparative cartilage after matrix-associated autologous chondrocyte transplantation at 3 Tesla-preliminary results," European Journal of Radiology, vol. 65, no. 1, pp. 72-79, 2008.

[179] S. Quirbach, S. Trattnig, S. Marlovits et al., "Initial results of in vivo high-resolution morphological and biochemical cartilage imaging of patients after matrix-associated autologous chondrocyte transplantation (MACT) of the ankle," Skeletal Radiology, vol. 38, no. 8, pp. 751-760, 2009. 
[180] S. Apprich, S. Trattnig, G. H. Welsch et al., "Assessment of articular cartilage repair tissue after matrix-associated autologous chondrocyte transplantation or the microfracture technique in the ankle joint using diffusion-weighted imaging at 3 Tesla," Osteoarthritis and Cartilage, vol. 20, no. 7, pp. 703-711, 2012.

[181] R. R. Regatte, S. V. S. Akella, A. Borthakur, J. B. Kneeland, and R. Reddy, "Proteoglycan depletion-induced changes in transverse relaxation maps of cartilage: comparison of $\mathrm{T}_{2}$ and $\mathrm{T}_{1 \rho}$," Academic Radiology, vol. 9, no. 12, pp. 1388-1394, 2002.

[182] F. Schick, "Whole-body MRI at high field: technical limits and clinical potential," European Radiology, vol. 15, no. 5, pp. 946959, 2005.

[183] M. T. Nieminen, J. Rieppo, J. Silvennoinen et al., "Spatial assessment of articular cartilage proteoglycans with Gd-DTPAenhanced $\mathrm{T}_{1}$ imaging," Magnetic Resonance in Medicine, vol. 48, no. 4, pp. 640-648, 2002.

[184] G. J. Stanisz and R. M. Henkelman, "Gd-DTPA relaxivity depends on macromolecular content," Magnetic Resonance in Medicine, vol. 44, no. 5, pp. 665-667, 2000.

[185] E. Wiener, K. Woertler, G. Weirich, E. J. Rummeny, and M. Settles, "Contrast enhanced cartilage imaging: comparison of ionic and non-ionic contrast agents," European Journal of Radio$\log y$, vol. 63, no. 1, pp. 110-119, 2007.

[186] R. B. Souza et al., "T $T_{1 \rho}$ MRI relaxation in knee OA subjects with varying sizes of cartilage lesions," The Knee, vol. 20, no. 2, pp. 113-119, 2013.

[187] U. Koller, S. Apprich, S. Domayer, R. Windhager, and S. Trattnig, "Magnetic resonance mapping of the rim of articular cartilage defects of the patella," International Orthopaedics, vol. 38, no. 1, pp. 67-72, 2014.

[188] D. J. Hunter, A. Guermazi, G. H. Lo et al., "Evolution of semiquantitative whole joint assessment of knee OA: MOAKS (MRI Osteoarthritis Knee Score)," Osteoarthritis and Cartilage, vol. 19, no. 8, pp. 990-1002, 2011. 


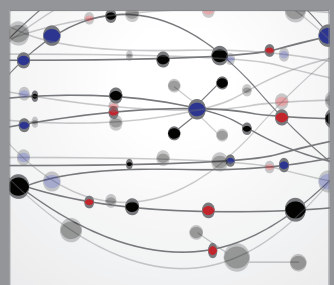

The Scientific World Journal
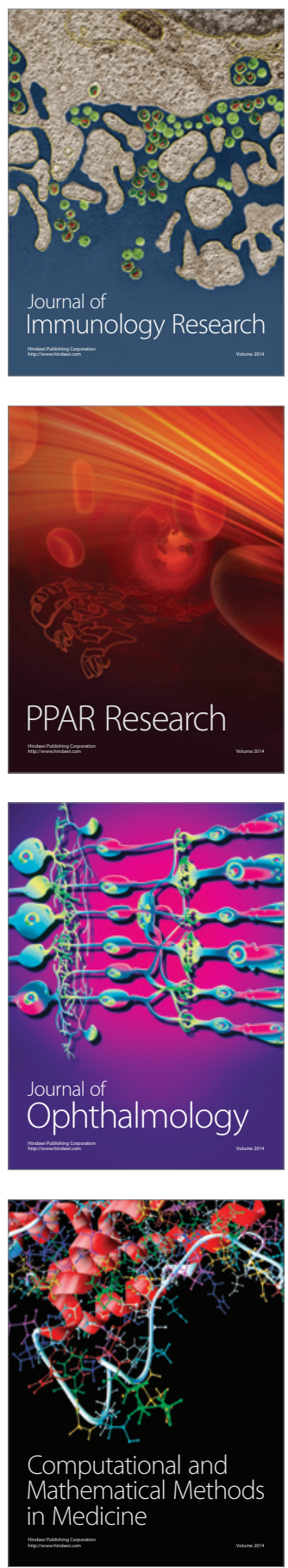

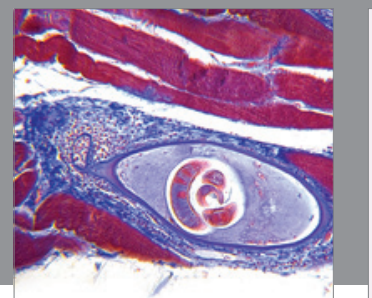

Gastroenterology

Research and Practice
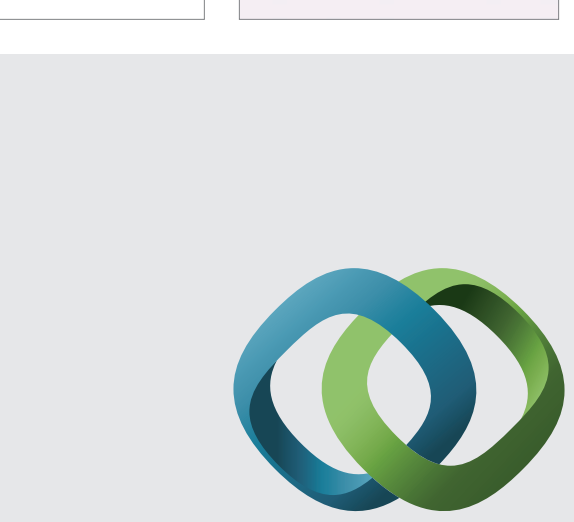

\section{Hindawi}

Submit your manuscripts at

http://www.hindawi.com
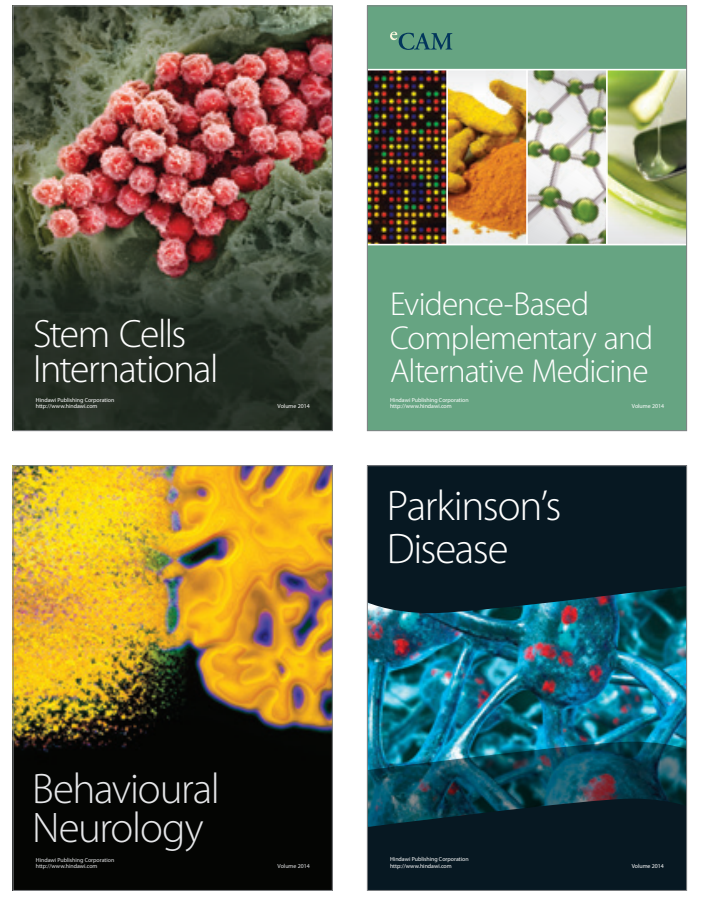
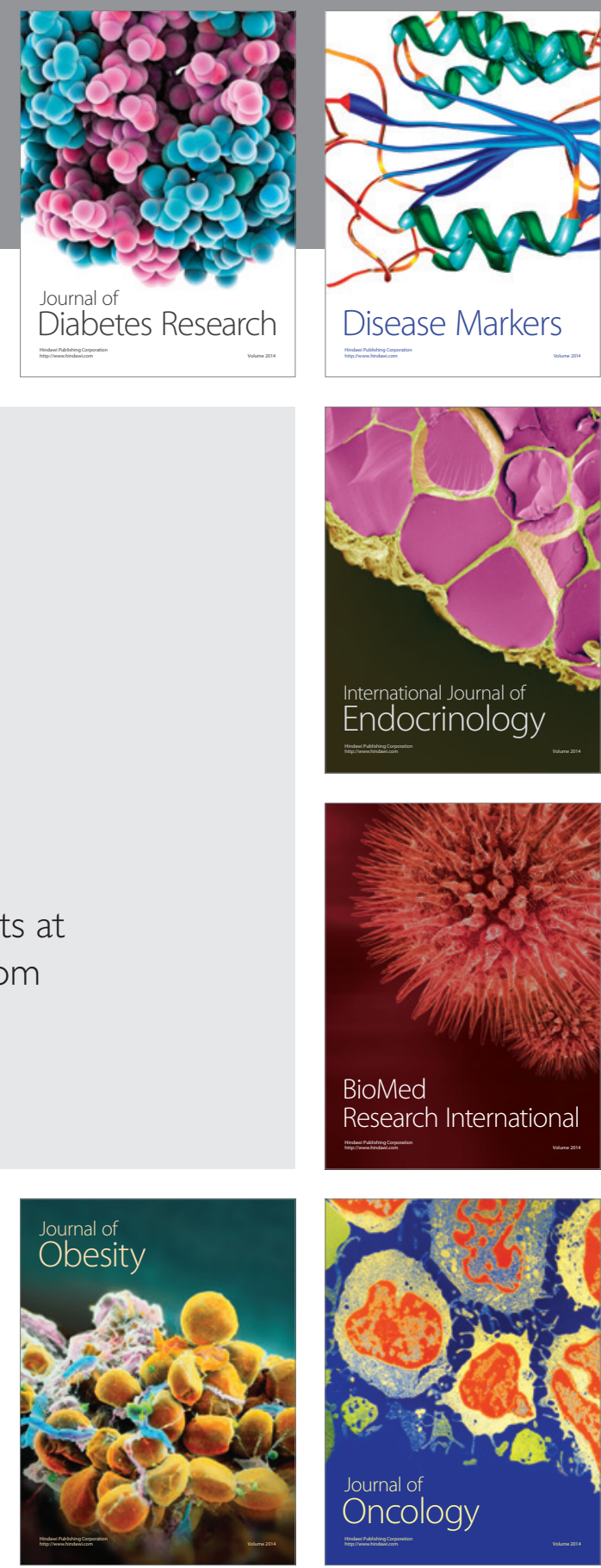

Disease Markers
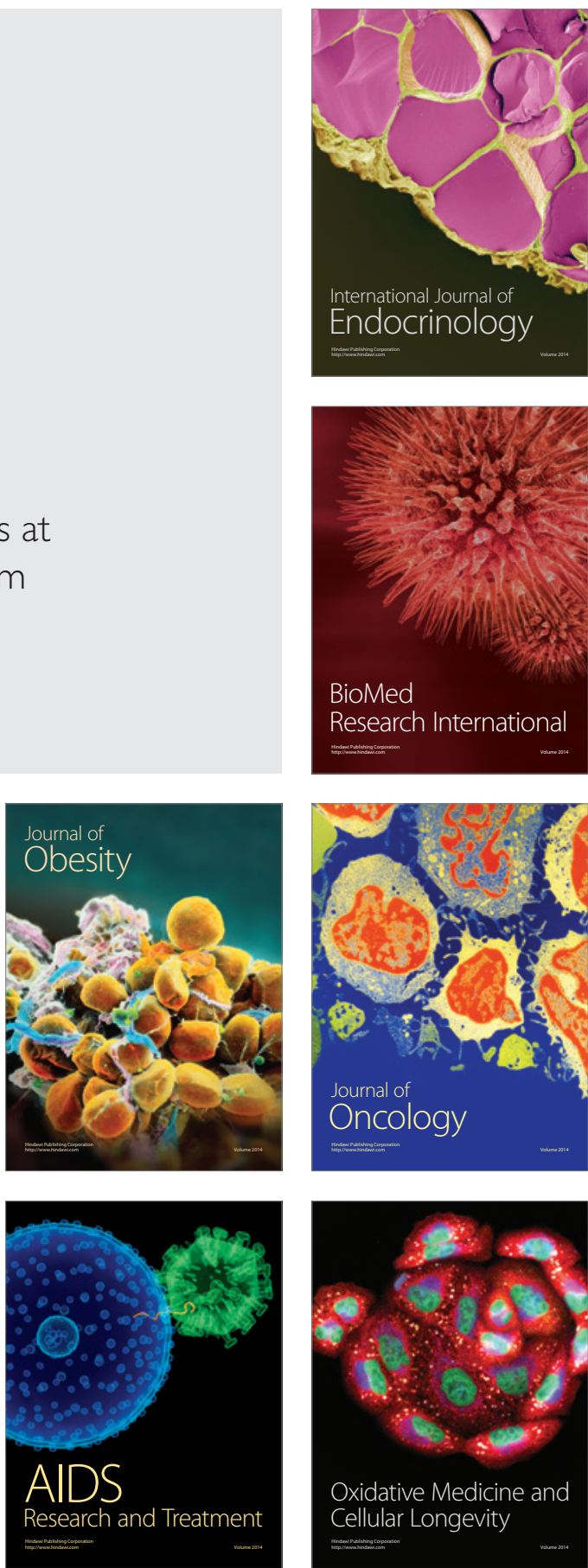